Acta Crystallographica Section A

Foundations of

Crystallography

ISSN 0108-7673

\section{Report of the Executive Committee for 2004}

\section{Meetings}

The IUCr sponsored the following meetings held during 2004:

Latin-American Course of Macromolecular Crystallography: from Crystal to Structure to Biological Function, Buenos Aires, Argentina, 22 March-6 April.

Second Moroccan School of Crystallography, El Jadida, Morocco, 10-14 May.

School on Diversity Amidst Similarity: a Multidisciplinary Approach to Polymorphs, Solvates and Phase Relationships, Erice, Italy, 9-20 June.

School on Electron Crystallography: Novel Approaches to Structure Determination of Nanosized Materials, Erice, Italy, 9-20 June.

AsCA '04, Hong Kong, People's Republic of China, 27-30 June.

XVI International School on Physics and Chemistry of Condensed Matter, Bialowieza, Poland, 1-10 July.

Gordon Conference: Electron Distributions and Chemical Bonding, South Hadley, MA, USA, 4-9 July.

ACA Annual Meeting, Chicago, IL, USA, 17-22 July.

Twelfth International Summer School on Crystal Growth, Berlin, Germany, 1-7 August.

ICCG-14 and ICVGE-12, Grenoble, France, 9-13 August.

Crystallography at High Pressure, Saskatoon, Canada, 18-21

August.

Crystallography at the Start of the 21st Century: Mathematical and Symmetry Aspects (satellite of ECM-22), 24-26 August.

22nd European Crystallographic Meeting (ECM-22), 26-31 August.

EPDIC IX, Prague, Czech Republic, 2-5 September.

7th Biennial Conference on High-Resolution X-ray Diffraction and Imaging (XTOP 2004), Pruhonice, Czech Republic, 7-10 September.

International Workshop on Nanomagnetism, Havana, Cuba, 14-18 November.

Course on Fundamentals of Modern Methods in Biocrystallography (BioCrys2004), Oeiras, Portugal, 19-26 November.

Recent Advances in Powder Diffraction, Cairo, Egypt, 27 November-2 December.

Regional School of Crystallography and Diffraction, Havana, Cuba, 4-9 December.

Micro- and Mesoporous Mineral Phases - Mineralogical, Crystallographic and Technological Aspects, Rome, Italy, 6-7 December.

The Executive Committee met in Budapest, Hungary, in August. The Finance Committee met in Copenhagen, Denmark, in March, and in Budapest, in August, to prepare its advice and recommendations on finances, establishment and staff matters. The most important items of business dealt with by the Executive Committee at its meeting, and in postal ballots, were:

editorial policy, pricing policy and subscription rates, consideration of appointments of new Editor-in-Chief and Editors for Acta Cryst.
Section F, approval of appointments of Co-editors, electronic publishing, archival policy, Special Issues, open access and other matters concerning the IUCr journals;

facility information pages for Journal of Synchrotron Radiation; contract with Blackwell Munksgaard;

approval of the audited accounts for the previous year;

General Fund estimates;

status of membership subscriptions;

investment policy;

funding and uses of the Publications and Journals Development

Fund and the Research and Education Fund;

sponsorship and financial support for meetings, young scientists' support;

Journal Grants Fund;

cooperation with databases, open-access databases;

progress with Volumes A, A1, B, C, D, E, F and G of International Tables and development of associated software; approval of new volume, development work to make International Tables available online;

review of contract with Springer (formerly Kluwer);

IUCr Newsletter;

World Database of Crystallographers;

promotional activities;

Ewald Prize;

sponsorship of other prizes;

discussion of the arrangements for the 2005 General Assembly and

Congress;

nominations for Officers of the IUCr and for Chairs and members of Commissions, proposals from the National Committees for these positions.

Other items dealt with in this way were:

uses of the Crystallographic Information File (CIF), work of the Committee for the Maintenance of the CIF Standard (COMCIFS), provision of checking services to other publishers, support of mmCIF project and CIF handling software;

consideration of publications, jointly with Oxford University Press, in the IUCr/OUP Book Series;

crystallography in Africa;

relations with other Scientific Unions;

review of the activities of the Commissions;

review of the activities of Regional Associates;

review of the reports of IUCr Representatives on other bodies; review of reports of the Committee on Crystallographic Databases.

Items concerning the Chester office were:

staffing requirements, preparation of new job descriptions and revision of staffing structure;

upgrading of office technology, provision of internet services. 


\section{Publications}

Volume 60 of Acta Crystallographica Sections A, B, C, D and E, Volume 37 of Journal of Applied Crystallography, Volume 11 of Journal of Synchrotron Radiation, the First Edition of Volume A1 and the Third Edition of Volume $\mathrm{C}$ of International Tables for Crystallography were published.

\section{Adhering Bodies}

A list of Adhering Bodies of the Union, with names and addresses of the Secretaries of the National Committees for Crystallography, was published as Annex IV to the Report of the Nineteenth General Assembly and International Congress of Crystallography [Acta Cryst. (2003), A59, 374-433].

\section{Work of the Commissions}

\subsection{Commission on Journals}

4.1.1. Overview. Overall, 10,175 pages were published in Acta Crystallographica in 2004, compared with 8,735 in 2003 and 7,905 in 2002. This represents an increase of $16 \%$ on the 2003 level; the number of printed pages increased to 5,507 from 5,316. 644 pages were printed for Section A (628 in 2003), 763 for Section B (821 in 2003), 1,694 for Section C (1,482 in 2003) and 2,406 for Section D (2,385 in 2003). Section E published 4,676 electronic only pages (3,419 in 2003). Average publication times increased for Section A (now 6.2 months) and C (2.3 months) and fell for Section B (4.8 months), Section D (4.3 months) and Section E (0.8 months). We have monitored closely the number of papers published in Sections A and B and discussed Special Issues as an initiative, much the same as for the Journal of Synchrotron Radiation in recent years. A survey of the contents of the IUCr journals is given in Table 1.

The citation impacts of IUCr journals continued to be high, occupying three of the top six ranking positions in Crystallography with Section B in the top position. Section D was ranked sixth; its impact factor was strongly influenced by a significant fraction of crystallization communications.

The overall withdrawal plus rejection rate for the journals was $26 \%$, up compared with last year $(20 \%)$. Looking into this, there is a noticeable effect from Section C (49\%), which in turn analyses as being heavily biased by high rejection rate by country of origin.

An open-access option was introduced for full articles on a fee payment basis by authors. In one case, however, a grant from the UK Joint Information Systems Committee allowed all UK papers to be published as open access this year.

Section $\mathrm{E}$ is attracting ever increasing numbers of electronic structure reports; the number of electronic pages produced in 2004 is approximately $85 \%$ of all of the printed pages published for Acta Cryst. in 2002! This success has required an expansion of the Section E Editorial Board. This is a major achievement to publish so many papers, all of which are of course citable and citation ranked by ISI.

A very significant effort has gone into the planning for Section F: Structural Biology and Crystallization Communications. New Section Editors (H. M. Einspahr and J. M. Guss) and a new Editorial Board were appointed. The first articles were made available online during autumn 2004. Extensive work has been made jointly with the Protein Data Bank by H. M. Einspahr concerning streamlined deposition-topublication methodologies. We acknowledge the Protein Data Bank here in this work.

This is my final Annual Report. I have greatly appreciated the high professional interactions and knowledge of the IUCr Chester staff, notably Peter Strickland (Managing Editor), Brian McMahon (Research and Development Officer), Andrea Sharpe (Promotions Officer) and Mike Dacombe (Executive Secretary), and indeed all the IUCr staff at Abbey Square, Chester, UK. I have enjoyed many science interactions with fellow IUCr Journals' Editors and Coeditors (Acta Cryst., J Appl Cryst. and J. Synchrotron Rad.) and with our submitting authors, as well as many fellow diffraction physicists, crystallographers and structural scientists who care deeply about the IUCr, through my nine years as Editor-in-Chief. I acknowledge also very good collaborations with the Executive and Finance Committees and with the IUCr Newsletter Editors. I thank here also, most heartily, the many scientists who helped me as referees. Overall I wish to record here that to have had the chance to contribute to the International Union of Crystallography by serving the IUCr Journals learned society style of publishing enterprise, as well as authors, subscribers and readers, has been a deeply fulfilling experience for me.

\section{J. R. Helliwell, Chair}

4.1.2. Acta Crystallographica Section A. Section A published 644 pages in 2004, as compared to 628 in 2003 . More important than the small increase of about $2.5 \%$ in the total number of pages is the increase of the number of pages devoted to Research Papers and Short Communications from 455 in 2003 to 619 in 2004. This includes 160 pages of a Special Issue published in September on New Information from Modern Charge Density Methods containing work presented at the Third European Charge Density Meeting ECDM-III at Sandbjerg Estate, Denmark. Thus, there were 459 pages devoted to science in 5 regular issues which per issue brings Section A roughly back to the level of 2002. The average publication time increased from 4.5 to 6.2 months. The journal also published an additional 308 pages of Abstracts from the ECM-22 meeting.

There were 78 full Research Papers (including 21 in the Special Issue), giving an average of 7.8 pages per article, comparable to the average length published in 2003. The number of Short Communications and Letters was 7, again comparable to 2003 (6). The percentage of withdrawn and rejected manuscripts remains high at 17 and $15 \%$, respectively. The subjects treated can be grouped, somewhat ambiguously, into the categories: geometry, twinning (16); algorithms, $a b$ initio calculations, novel experimental set-ups (14); diffraction theory, imaging methods, diffuse scattering (16); structure determination and refinement (13); electron densities $(5+21$ of the Special Issue). Co-editors do a good job with keeping the quality high, but the workload is unequally distributed. I am particularly proud that Section A published some papers with an outstandingly high potential for prolonged impact (in particular, a paper by G. Oszlányi \& A. Süto). On the other hand, I am sorry that one published paper had to be retracted. I thank Professor F. K. Larsen for his excellent work as Guest Editor of the Special Issue, and Professor S. Manninen for his collaboration in publishing two contributions from the Microsymposium on Quantum Crystallography presented at the Geneva Congress in 2002.

The geographical distribution of the origins of the articles (counted as integral or half-integral numbers) is Europe $61 \%$, the Americas $25 \%$, Asia + Australia 14\%. I would welcome a larger weight of the non-Europeans. In the pipeline for 2005 are two Special Issues, on Phase Transitions (first part to be published in January 2005) and on the MaThCryst Summer School (Nancy, France, 2005), two Lead Articles and one Topical Review (the latter to appear in March 2005).

D. Schwarzenbach, Editor of Section A 
Table 1

Survey of the contents of IUCr journals.

Acta Crystallographica

\begin{tabular}{|c|c|c|c|c|c|c|c|c|c|c|c|}
\hline \multirow[b]{2}{*}{ Vol. } & \multirow[b]{2}{*}{ Year } & \multirow{2}{*}{\multicolumn{2}{|c|}{$\begin{array}{l}\text { Number } \\
\text { of pages }\end{array}$}} & \multirow{2}{*}{\multicolumn{2}{|c|}{$\begin{array}{l}\text { Number } \\
\text { of papers }\end{array}$}} & \multicolumn{3}{|c|}{ Full Articles $\dagger$} & \multicolumn{3}{|c|}{$\begin{array}{l}\text { Short } \\
\text { Communications } \ddagger\end{array}$} \\
\hline & & & & & & \multicolumn{2}{|c|}{ Number } & $\begin{array}{l}\text { Average } \\
\text { length }\end{array}$ & Number & \multicolumn{2}{|c|}{$\begin{array}{l}\text { Average } \\
\text { length }\end{array}$} \\
\hline A56 & \multirow{4}{*}{2000} & 649 & & 82 & & 68 & & 8.2 ] & 14 & 6.0 & \\
\hline B56 & & 1127 & \multirow{3}{*}{5678} & 137 & \multirow{3}{*}{1501} & $124\}$ & \multirow{3}{*}{492} & $8.6\}$ & \multirow[b]{2}{*}{418} & 1.2 & \multirow{3}{*}{1.6} \\
\hline C56 & & 2179 & & 943 & & 591 & & 2.8 & & $1.3\}$ & \\
\hline D56 & & 1723 & & 339 & & $300\}$ & & $5.3\}$ & $39^{J}$ & $2.4^{\mathrm{J}}$ & \\
\hline A57 & \multirow{5}{*}{2001} & 803 & \multirow{5}{*}{7162} & 103 & & 78 & \multirow{5}{*}{527} & 8.9 & 25 & 5.6 & \\
\hline B57 & & 877 & & 110 & & $100\}$ & & $8.6\}$ & 10 & 1.6 & \multirow{4}{*}{1.7} \\
\hline C57 & & 1504 & & 545 & 1948 & 541 & & 2.7 & $4\} 85$ & 2.8 & \\
\hline D57 & & 1980 & & 390 & & $349\}$ & & $5.2\}$ & 41 & 3.3 & \\
\hline E57 & & 1998 & & 800 & & 795 & & 2.5 & 5 & 1.7 & \\
\hline A58 & \multirow{5}{*}{2002} & 630 & \multirow{5}{*}{7905} & 102 & \multirow{5}{*}{2148} & 65 & \multirow{5}{*}{605} & 8.0 & 37 & 2.8 & \\
\hline B58 & & 1088 & & 132 & & $115\}$ & & $8.9\}$ & 17 & 1.1 & \multirow{4}{*}{2.2} \\
\hline C58 & & 1570 & & 535 & & 531 & & 2.6 & 4 & 1.8 & \\
\hline D58 & & 2243 & & 457 & & $425\}$ & & $5.0\}$ & 32 & 2.3 & \\
\hline E58 & & 2374 & & 922 & & 918 & & 2.3 & 4 & 2.4 & \\
\hline A59 & \multirow{5}{*}{2003} & 628 & \multirow{5}{*}{8735} & 83 & & 58 & & 7.91 & 25 & 8.8 & \\
\hline B59 & & 821 & & 88 & & $81\}$ & & $9.8\}$ & 71 & 2.1 & \\
\hline C59 & & 1482 & & 482 & 2424 & 478 & 568 & 2.8 & 481 & 2.2 & 4.7 \\
\hline D59 & & 2385 & & 466 & & $429\}$ & & $5.2\}$ & 37 & 3.4 & \\
\hline E59 & & 3419 & & 1305 & & 1297 & & 2.5 & 8 & 1.8 & \\
\hline A 60 & & 644 & & 96 & & 78 & & 7.8 & 18 & 2.0 & \\
\hline B60 & & 763 & & 87 & & $84^{J}$ & & $\left.8.9^{\jmath}\right\} 5.8$ & $3\} 80$ & 3.3 & \\
\hline C60 & 2004 & 1694 & 10183 & 556 & 3061 & 554 & 624 & 3.0 & 2 & $4.0\}$ & 2.7 \\
\hline D60 & & 2406 & & 511 & & $462\}$ & & $4.9\}$ & 49 & $3.0^{\prime}$ & \\
\hline E60 & & 4676 & & 1811 & & 1803 & & 2.6 & 8 & 1.6 & \\
\hline
\end{tabular}

Journal of Applied Crystallography

\begin{tabular}{|c|c|c|c|c|c|c|c|c|c|}
\hline \multirow[b]{2}{*}{ Vol. } & \multirow[b]{2}{*}{ Year } & \multirow[b]{2}{*}{$\begin{array}{l}\text { Number } \\
\text { of pages§ }\end{array}$} & \multirow[b]{2}{*}{$\begin{array}{l}\text { Number } \\
\text { of papers }\end{array}$} & \multicolumn{2}{|c|}{ Full Articles } & \multicolumn{2}{|c|}{$\begin{array}{l}\text { Short } \\
\text { Communicationst† }\end{array}$} & \multicolumn{2}{|c|}{ Short items抹 } \\
\hline & & & & Number & $\begin{array}{l}\text { Average } \\
\text { length }\end{array}$ & Number & $\begin{array}{l}\text { Average } \\
\text { length }\end{array}$ & Number & $\begin{array}{l}\text { Average } \\
\text { length }\end{array}$ \\
\hline 33 & 2000 & 1468 & 259 & 190 & 6.1 & 43 & 4.1 & 26 & 1.3 \\
\hline 34 & 2001 & 798 & 140 & 93 & 7.1 & 21 & 3.5 & 26 & 1.5 \\
\hline 35 & 2002 & 760 & 128 & 83 & 7.2 & 25 & 4.0 & 20 & 1.6 \\
\hline 36 & 2003 & 1505 & 282 & 225 & 5.9 & 26 & 3.8 & 31 & 1.7 \\
\hline 37 & 2004 & 1041 & 170 & 110 & 7.7 & 27 & 4.0 & 33 & 2.3 \\
\hline
\end{tabular}

Journal of Synchrotron Radiation

\begin{tabular}{|c|c|c|c|c|c|c|c|c|c|}
\hline \multirow[b]{2}{*}{ Vol. } & \multirow[b]{2}{*}{ Year } & \multirow[b]{2}{*}{$\begin{array}{l}\text { Number } \\
\text { of pages } \S\end{array}$} & \multirow[b]{2}{*}{$\begin{array}{l}\text { Number } \\
\text { of papers }\end{array}$} & \multicolumn{2}{|c|}{ Full Articles } & \multicolumn{2}{|c|}{$\begin{array}{l}\text { Short } \\
\text { Communications }\end{array}$} & \multicolumn{2}{|c|}{ Short itemst: } \\
\hline & & & & Number & $\begin{array}{l}\text { Average } \\
\text { length }\end{array}$ & Number & $\begin{array}{l}\text { Average } \\
\text { length }\end{array}$ & Number & $\begin{array}{l}\text { Average } \\
\text { length }\end{array}$ \\
\hline 6 & 1999 & 1209 & 69 & 57 & 8.1 & 2 & 2.0 & 10 & 2.2 \\
\hline 7 & 2000 & 419 & 65 & 58 & 6.6 & 4 & 2.8 & 3 & 1.3 \\
\hline 8 & 2001 & 1255 & 376 & 70 & 5.4 & 280 & 2.9 & 26 & 1.1 \\
\hline 9 & 2002 & 413 & 93 & 68 & 5.5 & 2 & 4.0 & 23 & 0.7 \\
\hline 10 & 2003 & 475 & 108 & 77 & 5.5 & 5 & 2.2 & 26 & 0.8 \\
\hline 11 & 2004 & 512 & 119 & 85 & 5.5 & 3 & 3.3 & 31 & 1.0 \\
\hline
\end{tabular}

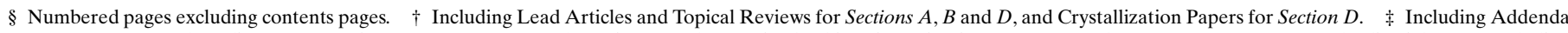

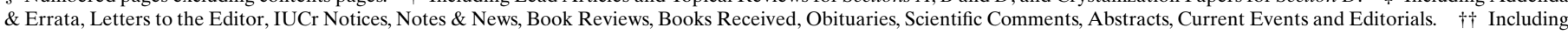

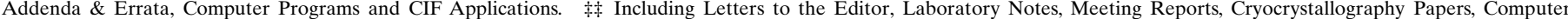

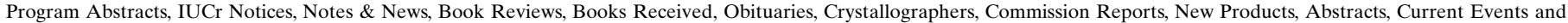
Editorials.

4.1.3. Acta Crystallographica Section B. The impact factor of Section B increased from 2.03 to 3.64. The current high value, which is almost certainly a consequence of the heavily cited 2002 Special Issue on databases, has brought Section B considerable visibility.
The 2004 statistics for Section B show that the numbers of full articles (84) was up by two from 2003, but that the average length of a paper dropped from 10 pages to 9 so that the total number of pages was down by $7 \%$. It may be that work is now being reported in a more concise way. Because access to archived CIFs and to other Supple- 
mentary Material is now easy, the number of tables in the printed papers can be reduced.

A comparison of the statistics for the years 2002-2004 shows that the distribution of articles between the inorganic, metal-organic and organic sections of the journal varies from year to year. The number of organic papers in the three years was 49,30 and 45 . No trend can be identified.

The electronic submission system first implemented in 2003 is now fully operational. The system is popular with both authors and editors. Time to publication (4.8 months) has dropped again (down from 5.4 months in 2003 and 6.2 months in 2002). Further decreases are less likely because the rate of communication is no longer a significant factor in time to publication. It should be noted that the 4.8 months is an average, and that significantly faster publication is possible if authors reply quickly to requests for revisions.

It is a pleasure to thank the Chester staff for their skill in making attractive pages while keeping the many tables, figures, and footnotes in logical positions relative to the text. The time spent by the Chester staff in editing authors' text is very much appreciated.

During 2004, Co-editor Mario Nardelli's long service to the Board came to a sudden and unexpected end. We will miss Mario's many contributions; he was greatly valued by authors, Co-editors and the Chester staff for his efficient and diplomatic handling of many manuscripts, and for his very positive attitude. We welcome new Coeditor Carl Henrik Görbitz to the Board.

\section{P. Brock, Editor of Section B}

4.1.4. Acta Crystallographica Section C. Section C continues to specialize in the rapid publication of high-quality studies of novel and challenging crystal and molecular structures. Publication times continue their downward trend with the majority of technically correct and well written papers appearing on line (http://journals. iucr.org/c) within one to two months of submission. In 2004, Section C published 533 papers (41 inorganic, 227 metal-organic, 285 organic) in a total of 1,686 pages - a $14 \%$ increase in papers and pages over 2003.

With the mandatory use of checkcif \{derived from PLATON Check.def [Spek (2003). J. Appl. Cryst. 36, 7-13]\} it is now rare for technically incorrect CIFs to be submitted by authors for consideration for publication in Section C. After review some $48 \%$ of submissions to Section $\mathrm{C}$ in the past year were either subsequently withdrawn by the authors or rejected. The principal reasons for this withdrawal/rejection rate were either that the text in the Comment section of the CIF was deemed not to provide the 'significant added value to the numerical data freely available in the CIF' as detailed in Notes for Authors, or that the text in the Comment section was very poorly crafted and difficult to understand.

Some changes have been made to the 2005 Notes for Authors in an attempt to improve the quality of initial submissions. To assist Coeditors with the initial review of new submissions we are now asking that the submitting author consider providing in the _publ_contact_ letter section of the CIF a brief statement of what is new, novel or interesting about the structure(s) in the submitted CIF that merits publication in the printed form in Section C. Given the ever increasing number of structures determined, the pressure on space in Section C is such we must serve our chemical- and materials-structure communities by keeping Section $\mathrm{C}$ as a premier outlet for the best crystal structures, both technically and scientifically.

It was with deep regret that we learned earlier this year of the death of Mario Nardelli, a highly-respected and long-time member of the Section C Editorial Board. I must also acknowledge and warmly thank G. R. Desiraju (University of Hyderabad, India), who has now retired from the Section $\mathrm{C}$ Editorial Board, for his services to Section $\mathrm{C}$ and the crystallographic community. I welcome R. Baggio (Argentina), M. R. J. Elsegood (UK), I. Guzei (USA) and O. Q. Munro (South Africa) as new members of the Editorial Board.

It is always a pleasure to thank the many Co-editors, referees and the Chester staff for their superb work in the preparation of Section $\mathrm{C}$; their fine efforts make my job as Editor much easier and I look forward to our continuing partnership.

\section{G. Ferguson, Editor of Section C}

4.1.5. Acta Crystallographica Section D. Section D has now been in operation for more than 10 years. In that time, a great deal has changed in biological crystallography, and changes are still occurring very quickly. The past few years have seen the advent of structural genomics, wide acceptance of structure-based drug design and a large growth in the number of macromolecular crystallography groups, both in academia and in industry. Robotic developments in protein crystallization are also having a major impact. In this environment, change is inevitable in the journals in this field. This year's report should be viewed in the light of these changes, outlined below.

In 2004, Section D had 13 issues, 12 of the standard type and one additional (in December) presenting the Proceedings of the 2004 CCP4 Study Weekend on Model Building and Refinement. In total, 512 individual papers were published on 2,406 pages. These were divided as follows:

\begin{tabular}{lrr}
\hline & Articles & Pages \\
\hline Research papers & 152 & 1245 \\
Tenth anniversary papers & 3 & 31 \\
Crystallization papers & 295 & 909 \\
Structural Genomics papers & 10 & 67 \\
Short Communications & 36 & 134 \\
Addenda and Errata & 12 & 12 \\
Obituaries & 2 & 6 \\
Letters to the Editor & 1 & 1 \\
Notes for Authors & 1 & 6 \\
\hline
\end{tabular}

The December Special Issue, Part 1, contained 20 articles based on the presentations on Model Building and Refinement, given at the 24th CCP4 Study Weekend in Leeds, UK, 4-5 January 2004, and was guest-edited by the meeting organizers, M. Noble and A. Perrakis. Methodological publications in the previous CCP4 issues are among the most often cited Section D papers and this series is very important both to the journal and in the field. It can be expected that the 2004 Proceedings will be a very popular resource for macromolecular crystallographers.

Sadly, two obituaries were published, mourning two great crystallographers who left us this year, David Blow and Carl-Ivar Brändén. Both of these pioneers contributed enormously to the foundations of protein crystallography, educated many followers, served in a number of distinguished scientific bodies and published many important books and papers, also in Section. D.

Acta Cryst. D60 (2004) was the last volume to contain Crystallization papers and Structural Genomics papers. From January 2005, these types of papers will be published in the on-line, electronic-only, new sister journal Acta Crystallographica Section F, entitled Structural Biology and Crystallization Communications. We welcome this transition, which should make publication of such papers easier and automatically connected with simultaneous submissions to the Protein Data Bank. Two of the Section D Co-editors, H. M. Einspahr and J. M. Guss, are the founding Editors for the new Section. This 
change may cause the next few issues of Section D to be slimmer than before, since in 2004 the Crystallization and Structural Genomics papers constituted about $40 \%$ (976 out of 2406) of all pages. We expect the overall impact will be positive, however, since Section D will be able to concentrate fully on structural and methodological papers, with the latter continuing to include papers on methods of crystallization. It will also give scope for the introduction of new initiatives, such as Topical Reviews, and we expect it to result also in an increase in the average citation index of Section D.

Very few submissions to Section D in 2004 were in the form of hard copy. The on-line system is working extremely well, and all authors (and Co-editors) appreciate it. For that, special thanks are in order to the staff taking care of Section D at the Chester Office, Louise Jones and Simon Glynn, for their excellent work.

\section{E. N. Baker and Z. Dauter, Editors of Section D}

4.1.6. Acta Crystallographica Section E. The year 2004 has seen another sustained period of growth for Section E. The numbers of papers published in each category were: inorganic 57, metal-organic 743 , organic 1,003 , a total of 1,803 papers in 4,676 pages. This is considerably more than double the size of the journal in its first year, 2001 (800 papers in almost 2,000 pages). The December 2004 issue was the largest ever, with 232 papers.

During the year, 253 papers were rejected and 203 withdrawn. This represents a total rejection and withdrawal rate of $20 \%$ of papers received. The distribution of papers by country of principal author was headed by the People's Republic of China (38.8\%), USA $(7.7 \%)$, Turkey $(6.8 \%)$ and UK (6.4\%).

The turn-round continues to be less than one month from receipt to publication; indeed, it has been reduced slightly this year, to an average of 0.8 months. It would be difficult to trim this much further!

The journal has received its first impact factor. At 0.453 , this is rather lower than we had hoped, but it is not very surprising for a journal of this kind, containing essentially structural reports of single compounds, and is higher than those of similar journals.

Some changes have been made to the submission process, which now automatically returns manuscripts to authors for further revision or the incorporation of an appropriate validation report form (VRF) if any level- $A$ alerts are generated by the checking procedures. Further, more substantial developments have begun and are expected to lead to a more streamlined procedure in the first half of 2005, when Notes for Authors will be extensively revised.

During the year we lost two Co-editors. M. M. Olmstead stood down temporarily through pressure of other commitments (she has taken up editorial work again recently). M. Nardelli sadly died; his loss will be missed by many in the international crystallographic community.

To cope with the increasing number of papers submitted to the journal, we appointed a number of new Co-editors during 2004, bringing the total number of Co-editors to 31: R. J. Butcher (USA), L. Eriksson (Sweden), R. D. Gilardi (USA), H. Ishida (Japan), B. KojicProdic (Croatia), C. Näther (Germany), C. Rizzoli (Italy), J. Simpson (New Zealand).

Nevertheless, the continuing increase in submission rates has led to a request by the editorial staff for further appointments and the process of selecting more candidates began at the end of the year. Meanwhile, the journal continues to be handled in the IUCr editorial office in Chester mainly by two members of staff (Gillian Holmes and Sean Conway), whose dedicated efforts are magnificent.

W. Clegg and D. G. Watson, Editors of Section E
4.1.7. Acta Crystallographica Section F. The new all-electronic Section F of Acta Crystallographica was launched in January 2005, making 2004 a very busy year for all concerned. A panel of distinguished and enthusiastic Co-editors was appointed ensuring that the high scientific and production standards that characterize Acta Crystallographica will be maintained in the new journal. [Co-editors: P. M. D. Fitzgerald (USA), W. N. Hunter (UK), G. J. Kleywegt (Sweden), W. C. Stallings (USA), Se Won Suh (Korea), I. Tanaka (Japan), T. C. Terwilliger (USA), J. D. Westbrook (USA); Co-editors with special responsibility for crystallization papers: A. M. Brzozowski (UK), P. J. Loll (USA), A. McPherson (USA), M. L. Pusey (USA), A. Vrielink (USA), A. Zagari (Italy).]

Section $\mathrm{F}$ aims to provide a home for short communications on the crystallization and structure of biological macromolecules. Structures determined through structural genomics initiatives or from iterative studies such as those used in the pharmaceutical industry are particularly welcomed.

An entirely new feature of Section F will be the close coordination of data submission to the Protein Data Bank (PDB) and preparation of mandatory items for inclusion in short structural papers. The preferred mode of data transfer from the database to the journal will be in the form of an mmCIF file. This will enable the generation of tables for publication and validation data for referees. One of the Section Editors (H. M. Einspahr) has worked closely with staff of the PDB (H. M. Berman and J. D. Westbrook) and the IUCr offices in Chester (Brian McMahon and Peter Strickland) to define the new mmCIF terms required for a complete description of a structure determination. Parallel efforts are being made to improve the communication between Co-editors, referees and authors.

The first issue of the new journal looks very good and our thanks go to the technical staff in Chester, especially Louise Jones.

\section{H. M. Einspahr and J. M. Guss, Editors of Section F}

4.1.8. Journal of Applied Crystallography. JAC published 1,049 pages in 2004 [1,009 in 2003, without the proceedings of the 2002 Small-Angle Scattering (SAS) conference]. The number of full articles was 110 in 2004 (119 in 2003 without 106 SAS articles, 83 in 2002). Shorter items like Short Communications, Laboratory Notes, Letters to the Editor etc. remained at the same level (about 25) during the last three years. The improved performance achieved in 2003 was thus maintained in 2004 and is expected to continue (226 manuscripts submitted in 2004 versus 216 in 2003). Nevertheless, further efforts are appropriate to make $J A C$ an even more attractive medium for crystallography-based work in all fields, also by a considerate appointment of a few new Co-editors to replace S. S. Hasnain, J. R. Helliwell, A. M. Moore, Å. Oskarsson, D. Pandey and H. Zimmermann, who will retire this year.

On-line submission is now almost exclusively used and works well. The publication time seems to have reached a constant level at about five months for editors/reviewers and 2.5 months for production. It has again been a pleasure to interact with the Chester staff who handled all matters arising with great competence and kindness.

\section{G. Kostorz, Editor of JAC}

4.1.9. Journal of Synchrotron Radiation. For 2004, JSR published 85 articles and a total of 512 pages in the six issues, corresponding to a $10 \%$ increase in both articles and number of pages as compared to 2003. In January 2004, a Special Issue on Diffraction Structural Biology (Guest Editor N. Yasuoka) was published based on selected papers from the International Symposium on Diffraction Structural Biology held in Tsukuba, Japan. We believe that the publication of selected papers from Workshops is an important service to the 
synchrotron-radiation community and we plan to continue this in the future.

Several informal discussions were held throughout the year among the Main Editors and Co-editors concerning issues such as increasing subscription rates and expanding the awareness of the synchrotronradiation community to JSR. 2004 marked the beginning of the Facility Information pages where one page per issue is devoted to each of the three third-generation hard X-ray sources (APS, ESRF and SPring-8). These pages provide an opportunity for these facilities to communicate important news and updates to the international community of synchrotron-radiation users.

Å. Kvick, D. M. Mills and T. Ohta, Editors of JSR

\subsection{Commission on International Tables}

Two important challenges mark the work of the Commission at present. The most important challenge is the development of the online version of the Tables, work on which will be demonstrated at the Florence Congress. The second challenge is the extension of the existing series of Tables and questions which the Commission has to discuss with the community:

- Are there fields not covered by the present volumes?

- Is the overlap between the volumes too extensive (or not enough)?

- Are printed tables of form factors still needed?

- Are printed volumes necessary at all?

- Do customers rather want a collection of articles covering a field or broader areas included in a single volume?

- Is the pricing adequate (value for money)?

- Do the community and potential customers outside crystallography think the title Tables for Crystallography appropriate?

The home page of the Commission is maintained at Tel Aviv University by U. Shmueli at the URL http://crystal.tau.ac.il/xtal/ comit/index.html.

The table below summarizes the sales and stock figures of all volumes:

\begin{tabular}{lrrrrrrrr}
\hline Volume & $A$ & $A 1$ & Brief $A$ & \multicolumn{1}{c}{$B$} & \multicolumn{1}{c}{$C$} & \multicolumn{1}{c}{$D$} & \multicolumn{1}{c}{$E$} & \multicolumn{1}{c}{$F$} \\
\hline First published & 1983 & 2004 & 1985 & 1993 & 1992 & 2003 & 2002 & 2001 \\
Sales in 2004 & 420 & 177 & 249 & 115 & 241 & 249 & 93 & 168 \\
Total sales & 10,056 & 177 & 6,690 & 3,068 & 3,773 & 534 & 426 & 1,315 \\
Stock at 31 & 53 & 546 & 214 & 485 & 675 & 917 & 311 & 659 \\
$\quad$ December & & & & & & & & \\
$\quad$ 2004 & & & & & & & &
\end{tabular}

4.2.1. Volume A. Space-Group Symmetry; Editor Th. Hahn. As the stocks of both Volume A and the Teaching Edition are very low, both will be reprinted in 2005 with corrections of printing errors and minor modifications. The volume still remains the flagship of the series and sells well.

4.2.2. Volume A1. Symmetry Relations between Space Groups; Editors H. Wondratschek and U. Müller. The volume was published in 2004. It contains a complete list of maximal subgroups of the space groups. Part 1 deals with group-theoretical aspects of space groups, group-subgroup relations and the underlying mathematical background. Part 2 contains complete listings of all maximal subgroups for each space group, including their general positions or their generators, their conjugacy relations and transformations to conventional settings. Part 3 lists the relations between the Wyckoff positions for every maximal subgroup of every space group including the cell transformations and coordinate transformations. In both Parts 2 and 3 , the infinitely many isomorphic subgroups have been included in a parametrized form.
4.2.3. Volume B. Reciprocal Space; Editor U. Shmueli. A third edition of Volume B is planned. The subdivision of the volume into five parts remains unchanged, but several changes are envisaged within most parts. Major revisions will be to the discussions of: applications of direct methods to macromolecular crystallography; electron diffraction and microscopy and their relation to structure determination; molecular modelling; and diffuse scattering.

4.2.4. Volume C. Mathematical, Physical and Chemical Tables; Editor H. Fuess. E. Prince retired as editor of Volume $\mathrm{C}$ last year. The members of the Commission would like to express their very great thanks to him for all his work. H. Fuess has taken over the role of Editor of Volume $\mathrm{C}$ and will work on the production of the next edition of this volume.

4.2.5. Volume D. Physical Properties of Crystals; Editor A. Authier. Volume D is off to a good start, with 534 copies sold so far. It has 536 pages and 18 chapters distributed within three parts: (1) Tensorial aspects of physical properties; (2) Symmetry aspects of excitations; (3) Symmetry aspects of structural phase transitions, twinning and domain structures. It is accompanied by a CD-ROM.

4.2.6. Volume E. Subperiodic Groups; Editors V. Kopsky and D. B. Litvin. The first edition of Volume $\mathrm{E}$ is still on sale. A list of corrections has been collected and will be discussed with users.

4.2.7. Volume F. Macromolecular Crystallography; Editors M. G. Rossmann and E. A. Arnold. In addition to Volume F, a version of Volume A on noncentrosymmetric space groups for use in protein crystallography is planned (Volume F1). Publication is planned for 2005.

4.2.8. Volume G. Definition and Exchange of Crystallographic Data; Editors B. McMahon and S. R. Hall. Volume $G$ is due to be published in 2005. It will be run to about 550 pages and will be accompanied by a CD-ROM.

\section{H. Fuess, Chair}

\subsection{Commission on Aperiodic Crystals}

The activities of the Commission were focused on the organization of international conferences and the coordination of activities between the different communities working on quasicrystals and incommensurate structures.

The Commission continued to promote activities on the crystallography of aperiodic crystals at national and international meetings, including the annual meeting of the Society of Crystallographers in Australia and New Zealand (SCANZ), held at Marysville near Melbourne, and the annual conference of the German Crystallographic Association (DGK) in Jena. At the European Crystallographic Meeting ECM-22 (26-31 August 2004, Budapest, Hungary) a Microsymposium on New Developments in the Field of Aperiodic Crystals was chaired by G. Chapuis and W. Steurer, and a Keynote Lecture was presented by S. van Smaalen.

The dates for the next Aperiodic meeting (Aperiodic 2006) are 17-22 September 2006; it will be held in Zao (near Sendai), Japan, and organized by A. Yamamoto (Chair), An Pang Tsai (Vice-Chair), Y. Gotoh, Y. Michiue, Y. Miyazaki and K. Saitoh.

A Workshop on aperiodic crystallography will take place on the first day of the Florence Congress (23 August 2005). The goal of this Workshop is to give an overview of the state of the art of crystallographic analysis of incommensurate crystals and quasicrystals. Introductory lectures will present the fundamentals of the superspace theory for the description of incommensurate crystal structures. The afternoon session will be devoted to recent developments and applications of superspace crystallography. 
The Commission maintains internet pages at the web site of the IUCr at http://www.iucr.org/iucr-top/comm/capd/index.html. A web site on all aspects of the crystallography of aperiodic crystals is maintained by the special interest group (SIG) on aperiodic crystals of the European Crystallographic Association. It is maintained by M. Dusek (Prague, Czech Republic), and it can be found at http:// www-xray.fzu.cz/sgip/aphome.html.

\section{S. van Smaalen, Chair}

\subsection{Commission on Biological Macromolecules}

The Commission has continued to evaluate and recommend for IUCr support proposals to hold meetings, Workshops and Schools. Two such meetings will be held in Europe in 2005.

A number of regional meetings of the IUCr were held in 2004, which attracted strong support from the macromolecular structure community. The meeting of the Asian Crystallographic Association was held in Hong Kong, People's Republic of China, in June; of the European Crystallographic Association in Budapest, Hungary, in August; and of the American Crystallographic Association in Chicago in July. Macromolecular crystallography represented the single largest scientific discipline at each of the meetings. The Protein Data Bank awarded prizes for the best student poster in macromolecular crystallography at all three meetings.

The publication of Section F of Acta Crystallographica in January 2005 marks a major milestone for the IUCr. Section F will publish protein structure, structural genomics and crystallization communications. This is the second all-electronic publication of the $\mathrm{IUCr}$ and promises innovation in the coordination of data deposition and publication for macromolecular crystallography.

The Commission plans to hold an Open Meeting during the IUCr Congress in Florence on software standards in macromolecular crystallography.

\section{J. M. Guss, Chair}

\subsection{Commission on Charge, Spin and Momentum Densities}

The main event in 2004 was the Gordon Research Conference (GRC) on Electron Distributions and Chemical Bonding, which was very successfully chaired by J. C. H. Spence and co-chaired by C. Gatti: 96 attendees (55\% less than 40 years old) from Europe (55\%), North America (35\%), and Asia and Australia (10\%). The main topics were bonding in solids, surface, electron diffraction versus $\mathrm{X}$-ray diffraction, cutting-edge science such as electron density in large macromolecular systems (experimental and theoretical) or photocrystallography. The meeting's atmosphere was excellent owing to a very good selection of topics, speakers and posters. This GRC, as well as that held in 2001, confirmed that the field is renewing and attracts many new and young researchers. The next GRC will be held in 2007 (C. Gatti as Chair, D. Jayatilaka as Co-Chair). Another activity in this field was one session of ECM-22 in Budapest, Hungary.

Concerning the momentum density and inelastic scattering community, the most important activity was the 5th International Conference on Inelastic X-ray Scattering held at APS, Argonne (Illinois, USA) in September 2004 (http://www.ixs04.aps.anl.gov) chaired by E. Alp and co-chaired by A. Bansil.

It has to be noted that charge density research is very alive in Germany, thanks to our German colleagues, who convince the DFG to organize a 'schwer Punkt' on 'experimental electron distribution and chemistry', which led to 20 new grants on electron-density projects in chemistry. This is particularly interesting because it attracted many chemists who are willing to enter the field of charge density. It is, however, a singularity by comparison with most developed countries where the field is not promoted enough.

The new Commission project entitled Constrained Experimental Wavefunction proposed by D. Jayatilaka now includes six groups that are using and testing the possibilities of the TONTO program [F. K. Larsen, B. Iversen (Denmark); M. A. Spackman (Australia); H.-B. Bürgi (Switzerland + ESRF); Kozicek (Slovakia); J. A. K. Howard (UK); and C. Lecomte (France)].

\section{Lecomte, Chair}

\subsection{Commission on Crystal Growth and Characterization of Materials}

The Commission has continued in 2004 the promotion and organization of Schools aimed at the diffusion of the crystal growth discipline among young scientists, particularly from developing countries. Furthermore, the Commission also recommended the sponsorship of several other events related to crystal growth. More specifically, the Commission was actively involved in the following meetings and schools:

(1) 12th International Summer School on Crystal Growth (ISSCG12), held in Berlin, Germany, 1-7 August 2004. This was a very successful School that attracted over 120 young participants from 28 countries. The technical programme included 30 excellent lectures and tutorial seminars held by internationally recognized specialists. It is worth mentioning that 66 students from developing countries were supported by the organizers thanks to the generous sponsorship of various agencies and organizations, among which was the IUCr. The School proceedings were published by Elsevier Science in a book entitled Crystal Growth - from Fundamentals to Technology, edited by G. Mueller, J. J. Metois and P. Rudolph.

(2) International Conference on Crystal Growth (ICCG-14), held in Grenoble, France, 9-13 August 2004, in conjunction with the 12th International Conference on Vapour Growth and Epitaxy. This is a most important forum for crystal growers and many members of our Commission were involved in the organization of the different sessions. The programme included 943 papers, ranging from growth of traditional semiconductors to oxide to nanomaterials and nanoclusters. The proceedings, edited by T. Duffar, M. Heuken and J. Villain, are partly published in J. Cryst. Growth and partly distributed on CD-ROM. The conference was sponsored by the IUCr.

(3) International Workshop on Nanomagnetism, La Habana, Cuba, 15-19 November 2004. The Commission supported this meeting and recommended its sponsorship by the IUCr. The meeting was considered successful as it collected about 85 participants from 17 countries. It is important to note that one quarter of the participants were students, six of which could participate thanks to IUCr sponsorship. The proceedings of the meeting should appear soon in Journal of Magnetism and Magnetic Materials.

(4) The Commission ended the activity of the triennium 2002-2005 positively with an international School which took place in Puebla de los Angeles, Mexico, 7-11 March 2005. The main objective of this meeting was to provide basic crystal growth concepts along with an overview of growth technologies. The participants were about 45, most of them from Mexico, but with a consistent participation from other Latin-American countries. 16 lecturers from Canada, France, Germany, Uruguay, Mexico, Spain, Switzerland and USA gave tutorial lectures on specific subjects such as computer modelling of growth processes, epitaxy of semiconductors, bulk growth of oxides and semiconductors, organic materials for NLO, ferroelectric materials, solution growth of biocrystals, structural studies and defects in 
real crystals. Four members of our Commission were enrolled as lecturers at the School.

\section{R. Fornari, Chair}

\subsection{Commission on Crystallographic Computing}

The activities of the commission included:

(1) The proposal and implementation of nine computing-related Microsymposia for the Florence Congress. The subjects of the Microsymposia address the interests of macromolecular, smallmolecule, charge-density and powder-diffraction researchers.

(2) The organization of the pre-conference computing School to be held in Siena. This School addresses, in particular, scientific software development rather than the latest science. There is a large need for a next generation of scientists knowledgeable in software development in view of the upcoming retirement of the current generation of developers. Traditional computer software is written in a language (Fortran) that is no longer mainstream. The current trend is $\mathrm{C}++$, toolboxes, graphical user interfaces and scripting languages.

(3) Two issues of a Newsletter (http://www.iucr.org/iucr-top/comm/ ccom/newsletters) appeared, edited by Commission member L. M. D. Cranswick. Every issue contains invited articles around a theme. For example, issue No. 4 contains contributions in the context of 'Restraints, Constraints and Using Extra Observables'.

(4) A web site is maintained at http://www.iucr.org/iucr-top/comm/ ccom/.

A. L. Spek, Chair

\subsection{Commission on Crystallographic Nomenclature}

The activity of the Commission is through its working groups.

(1) Working Group on Synchrotron Radiation Nomenclature (D. M. Mills, Chair). The group has produced a report regarding the uses of the terms 'brilliance' and 'brightness'. Its recommendation is that the quantity characterizing the radiation properties of thirdgeneration sources, namely the number of photons emitted per second per bandwidth per unit solid angle and unit area of the source [photons s${ }^{-1} \mathrm{~mm}^{-2} \mathrm{mrad}^{-2}(0.1 \% \text { bandwidth })^{-1}$ ] is best described by the term 'spectral brightness'. The report has been approved by the members of the Commission and will be printed in $J S R$.

(2) Working Group on Phase Identifiers (I. D. Brown, Chair). The working group is charged with developing a crystallographic phase identifier. It has examined a number of ways to formulate an identifier that will uniquely label crystal structure phases stored in a computer database and has coordinated its efforts with the Committee developing an IUPAC-NIST Chemical Identifier (INChI). The final report of the working group is essentially complete but is being reviewed by people in the field who are not members of the working group. It is expected that the report will be submitted in the near future.

(3) The IUCr Representative on the IUPAC Interdivisional Committee on Terminology, Nomenclature and Symbols, S. C. Abrahams, reports a high level of activity in 2004 after the appointment of a new Chair. Among matters of interest to the IUCr is the question of inserting a space or not between numerical values and their unit symbol, for example, between ' 2.5 ' and ' $\mathrm{\AA}$ ' or between a value and its uncertainty within brackets. The current ISO 31-0 requires a thin (half) space; however, the draft ISO/IEC 80000 follows CODATA style and has no space. Another proposal is the use of the name 'uno', symbol $\mathrm{U}$, for the unit one so that dimensionless numbers may be treated in the same way as all other SI units. Thus, a second phase in a material detected at a $15 \mu \mathrm{g} / \mathrm{kg}$ level, for example, would be expressed as $15 \mathrm{nU}$ (15 nanouno) of that phase. Among other advantages, the proposed unit eliminates the present widespread and sometimes ambiguous use of abbreviations such as p.p.m. and p.p.b.

(4) The Chair of COMCIFS (I. D. Brown), reports that during 2004 COMCIFS has put considerable energy into the publication of Volume $\mathrm{G}$ of International Tables for Crystallography, the volume that will contain a comprehensive account of the CIF project. It is expected to be published in 2005 .

\section{A. Authier, Chair}

\subsection{Commission on Crystallographic Teaching}

The members of the Commission appointed by the Geneva General Assembly in August 2002 were: R. B. Neder (Chair, Germany), J. D. Barnes (USA), G. Chapuis (Switzerland), L. M. D. Cranswick (Canada), K. Crennell (UK), M. E. Kastner (USA), K. Ogawa (Japan), S. Parthasarathy (India), V. S. Urusov (Russia).

The Commission was not active for the first two years and in September 2004 the Executive Committee decided to appoint P. Spadon as Chair.

Contacts were established via e-mail and the first action was to provide suggestions for the preparation of the scientific programme of the Florence Congress. During the same Congress, a meeting is planned in order to agree on the future activity of the Commission and for this it will be particularly important to suggest new qualified and active members to be appointed for the triennium 2005-2008.

Recently, contacts have been established with the Informal Work Group on Mathematical and Theoretical Crystallography (MaThCryst) in order to contribute to the organization of a Winter School in Havana, Cuba, with young scientists of the Caribbean region as the potential audience. The programme and list of speakers are under discussion.

P. Spadon is member of the Scientific Programme Committee of the Florence Congress.

\section{P. Spadon, Chair}

\subsection{Commission on Electron Diffraction}

The highlight of 2004 has been the School for Electron Crystallography, held at Erice, Sicily, 9-20 June at the NATO Advanced Study Institute. This was capably organized by T. Weirich, J. Labar and X. Zou. About 90 participants and lecturers attended over a week of lectures on all aspects of electron crystallography, including microdiffraction, atomic-resolution imaging and new approaches to solving nanocrystalline structures by electron diffraction. Other topics included polymorphism, phasing electron diffraction data, multiple scattering, symmetry determination, laboratory and software sessions, atomic resolution imaging, electron diffraction from organics and zeolites, charge-density measurement, lattice parameters, and gas-phase diffraction. A recurring theme was the ability to treat small crystals whose size prevents the use of X-ray diffraction, and the power of imaging for the study of defects.

The development of time-resolved electron diffraction continued with the first US National Workshop on Ultrafast Electron Microscopy at Lawrence Livermore Laboratories on 16-17 April 2004. 51 participants from Universities, National Laboratories and companies attended two days of lectures on fast imaging and diffraction with high-energy electron beams, including those planning to use the electron accelerators for synchrotrons directly for this purpose. The 
current instruments at Caltech, Brown, University of Toronto and Florida State were reviewed, together with new ones planned at Michigan State, University of Illinois and Berkeley. The pioneering imaging instrument in Berlin will soon move to Livermore. Talk topics included the design of photocathodes, electron lenses, detectors and space-charge limitations and pulse compression. The much larger cross section for electron scattering than for X-rays was emphasized, while the source brightness of field-emission electron sources is known to be brighter than that of current generation synchrotron-undulator systems. The attainment of $700 \mathrm{fs}$ electron diffraction results in single shot by Cao et al. at Florida was discussed, as was Zuo's iterative phasing of continuous diffraction data by the Fienup-Gerchberg-Saxton method. Applications in materials science and biology were reviewed.

The Gordon Conference on charge-density measurements held from 4 July 2004 included a morning session on electron diffraction methods for accurate charge-density measurement. The amplification of sensitivity at low angles in electron scattering over X-rays was emphasized (owing to the Mott-Bethe relationship), while the ability to obtain extinction-free measurements by using an electron probe smaller than one mosaic block was also described, with applications to several oxides.

About 20 students, postdocs and industrial researchers attended a week-long School in electron diffraction at the National Center for Electron Microscopy at Lawrence Berkeley Laboratory, Berkeley, CA, USA, starting on 19 April 2004. Lectures by L. Marks, J. Zuo, W. Sinkler, J. C. H. Spence, U. Dahmen, A. Eades and R. Kilaas covered all aspects of electron crystallography, including CBED, SAD, diffuse scattering, powder patterns for phase identification, combining SAD with HREM, and basic theory, from dynamical theory, Bloch waves, channelling and multislice, to direct methods. Special topics included diffractive imaging and the precession camera. Afternoons were devoted to practical classes and computer use for simulations. One set of programs for most electron crystallography purposes, now executable on the web for all to use, can be found at http:// emaps.mrl.uiuc.edu/. A similar School may be held next year.

\section{J. C. H. Spence, Chair}

\subsection{Commission on High Pressure}

High-pressure crystallography remains a very active field with a wide variety of technical developments and new scientific applications. For this reason, one of the most important goals of the Commission is to help the community to exchange know-how and disseminate new achievements. It is doing this by organizing special Workshops in each of the two years between the triennial IUCr Congresses. These Workshops also help to broaden the field and attract new people. One of the main concerns is to support and promote participation of young scientists.

In 2004, this Workshop was hosted by the Canadian Light Source at Saskatoon, 18-21 August. It was sponsored jointly by the IUCr, the President of the University of Saskatchewan, the Canadian Light Source Inc., the Canadian Institute for Synchrotron Radiation, the Steacie Institute for Molecular Sciences of the National Research Council of Canada, ALMAX Industries and Blake Industries Inc. Commission member J. Tse was the organizer.

This year's Workshop tried to embrace the full width of highpressure crystallography. The scientific programme therefore covered many scientific and technological areas of interest to the Commission. The Workshop was arranged into 11 sessions over three and a half days. Each session focused on a particular subject and was led by a
Keynote Lecture introducing the state-of-the-art of the field. There were a total of 47 oral presentations covering diverse topical subjects such as structural studies on biological materials, liquid-liquid transition, amorphous solids, chemistry and novel materials and structures, superconductivity and magnetism, computational crystallography and the latest development in instrumentation and methodologies for structural determination. A large portion of the presentations was given by young scientists (10 lectures by recent postdocs and students). In addition to formal presentations, a poster session with 22 contributions provided an alternative forum for further scientific discussions. The social highlight was the Workshop dinner held at a Saskatchewan ranch and included unusual but entertaining activities such as a corral maze, a tour in a horse wagon and bare-back horse riding. It ended with a bus drive through the Canadian night displaying a magnificent aurora borealis.

The Workshop was attended by close to 90 participants from 13 different countries. The Organizing Committee is particularly grateful to the financial support from the IUCr. A total of 20 young scientists benefited from its travel support. Poster prizes were awarded to young scientists to encourage their participation.

The Workshop in Saskatoon was also the only major meeting of the Commission members in 2004. Five members were present. The main items of business concerned the upcoming Florence Congress. Commission member J. B. Parise represented the Commission on the Programme Committee. The Commission will sponsor six Microsymposia on six consecutive half-days from the morning of 26 August until the afternoon of 28 August. In addition, the Commission was able to place two Keynote speakers (M. McMahon and J. Tse) in the programme. We also decided to propose two Open Commission Meetings on the subjects of technical developments (responsible Commission member I. N. Goncharenko) and high-pressure singlecrystal diffraction (responsible Commission member J. S. Loveday). With regard to the Commission Workshop in 2006, we decided to hold this in Dubna, Russia. Local organizers have been contacted and local support has been approved. For 2007, the Diamond synchrotron source in the UK is planned as host. Commission member J. S. Loveday will put together a Local Organizing Committee.

The Commission's home page is maintained by Commission member J. S. Loveday and continues to update the high-pressure community on information with respect to software, future and past meetings, central facilities, scientists and publications in the highpressure field. The home page can be accessed at http://www.iucr.org/ iucr-top/comm/chp/index.html.

M. Kunz, Chair

\subsection{Commission on Inorganic and Mineral Structures}

The contacts among the members and consultants of the Commission (CIMS) have been maintained mainly by e-mail and the web site at http://www.lcm3b.uhp-nancy.fr/cims/ administered by consultant member M. Nespolo. Some members met on the occasion of ECM-22 in Budapest, Hungary, 26-31 August 2004. At ECM-22, members of CIMS were active as conveners (M. Nespolo: Investigation techniques in mineral science; J. Rius: Advances in powder diffraction methods) and speakers (W. Depmeier and G. Ferraris). As a satellite of ECM-22, M. Nespolo organized the Conference entitled Crystallography at the Start of the 21st Century: Mathematical and Symmetry Aspects, Budapest, 24-26 August 2004; the satellite was supported by CIMS and members M. Nespolo and W. Depmeier presented lectures. 
The main activity of the Commission in 2004 has been the organization of the meeting Micro- and Mesoporous Mineral Phases Mineralogical, Crystallographic and Technological Aspects. The meeting took place in Rome, Italy, 6-7 December 2004 and was financially supported by the IUCr and the Italian National Academy of Lincei. The attendees were more than 100 from 20 different countries, including extra-European ones. 32 contributions were presented orally and 53 as posters. Concerning members of CIMS: G. Ferraris was member of the Organizing Committee and speaker; W. Depmeier and L. B. McCusker were speakers. The extended abstracts filled a Pre-Print book of 324 pages; the 12 invited lectures are in press as Volume 57 of the series Reviews in Mineralogy and Geochemistry of the Mineralogical Society of America (Series Editor J. J. Rosso; Volume Editors: G. Ferraris and S. Merlino). A number of other contributions have been submitted for a special issue of the European Journal of Mineralogy dedicated to the CIMS meeting.

Besides the activity reported above, the following members of CIMS have reported to the Chair activity related to the purposes of the Commission:

D. Yu. Pushcharovsky represents CIMS on the Programme Committee of the Florence Congress and was convener of the Symposium Crystal Structure of Minerals: Topology and Classification at the 32nd International Geological Congress (Florence, 20-28 August 2004).

G. Ferraris was convener of the Symposium Microstructures, Modularity, Modulations in Minerals at the 32nd International Geological Congress and co-author (with E. Makovicky and S. Merlino) of the IUCr/OUP Monograph Crystallography of Modular Materials. He is a member of the Programme Committee and convener of the 19th Meeting of the International Mineralogical Association (IMA), Kobe, Japan, 23-28 July 2006, and convener of a Microsymposium at the Florence Congress.

L. B. McCusker lectured at NHSC-33 (Pune, India), the 14th International Zeolite Conference (Cape Town, South Africa), EPDIC-9 (Prague, Czech Republic); she was Guest Co-editor of a Special Issue of Z. Kristallogr. devoted to Structure Determination from Powder Diffraction Data; she is a member of the Organizing/ Programme Committees of EPDIC-10 (Geneva, Switzerland, 2006) and ZMPC 2006 (Yanago, Japan, 2006); she co-maintains the IZA web sites on zeolites at http://www.iza-online.org/ and http://www. iza-structure.org/.

M. Nespolo is the organizer of the International School on Mathematical and Theoretical Crystallography, Nancy, France, June 2005, supported by CIMS.

M. Matsui is Chair of the Meeting Secretariat for IMA-2006 (Kobe, Japan) and Editor of Physics and Chemistry of Minerals.

W. Depmeier is co-organizer of the meeting Mineralogical Museums (St Petersburg, Russia, June 2005) and President of the German Crystallographic Association.

J. Rius is a member of: the ESRF Review Committee in the Chemistry Area; the Spanish National Committee for Crystallography; and the Scientific Committee of EPDIC-9. He is Chair of the Special Interest Group (SIG8) of the ECA and an Associate Editor of the European Journal of Mineralogy. He is a convener of a Microsymposium at the Florence Congress.

\section{G. Ferraris, Chair}

\subsection{Commission on Neutron Scattering}

In 2004, several changes occurred concerning neutron sources worldwide and, in particular, in Europe. Some sources are being refurbished or expanded such as ILL (France) or ISIS (UK); for others, the decision was taken to shut them down in the near future for example, the research reactor in Jülich (Germany). Nevertheless, the situation for the users of neutron sources in 2004 was favourable thanks to reliable sources all over the world and the commissioning of new sources such as the new source FRM-II in Munich (Germany). Additionally, new generation neutron sources are being built and making good progress: the SNS in USA and the J-PARC in Japan. From 2004 onwards, the access to European sources is supported by the so-called NMI3 Project (Integrated Infrastructure Initiative for Neutron Scattering and Muon Spectroscopy) that falls within the activity 'Structuring the European Research Area - Research Infrastructures' of the EU 6th Framework programme. This programme is a continuation of the successful programme to finance the exchange of scientists and the mutual use of sources that has already been running for more than 10 years.

The new reactor FRM-II in Munich (Germany) became critical in March 2004. After the first criticality of the reactor, numerous lowpower tests were performed until April 2004. Full power was reached in August 2004 for the first time and the commissioning was completed successfully two months later. The official inauguration occurred in the middle of 2004 and routine operation started in the spring of 2005 after some teething troubles. In 2004, the decision was taken to shut down the reactor FRJ-2 at Forschungszentrum Jülich (Germany) by May 2006. A contract to install an outstation of the Forschungszentrum Jülich at the site of the FRM-II was agreed between the Technical University Munich and the Forschungszentrum Jülich in June 2004. Seven instruments for neutron research will be transferred to Munich and operated there by the Forschungszentrum Jülich. The transfer of the instruments is expected to start at the end of 2005.

In France, the situation of the reactor Orphée has been secured for the years to come after a long uncertainty about finances.

ISIS, the world's leading spallation neutron source at the Rutherford Appleton Laboratory (UK), offers research opportunities in the fields of physics, chemistry, materials science, geology, engineering and biology. A $10 \mathrm{~Hz}$ second target station is being built in order to meet the increased user demands for lower energy and longer wavelength pulsed neutrons for the study of structure and dynamics in increasingly complex systems. Seven instruments are to be built from 2006 onwards with the baseline specifications of these instruments completed at the end of June 2004. The completion of the target installation is expected to occur in 2007, and the experimental programme is expected to start in 2008. The second target station will open new opportunities in biomolecular science, nanoscale science, advanced materials and soft condensed matter.

In 2000, the ILL (Institut Laue-Langevin) in Grenoble (France) launched the so-called Millennium Programme. The aim of this programme is to renew the instrumentation at this source. Some instruments have already been completed. Additionally, a refit programme to secure the long-term operation of the reactor is successfully on the way and will be finished in 2006. Owing to this refit programme, the number of operation cycles is reduced. It should be mentioned that the cooperation between the ILL and the ESRF (European Synchrotron Radiation Facility) in Grenoble is running successfully. The Partnership for Structural Biology (PSB) contributes to this success. The PSB was founded by one national and three European research institutes: the Institut de Biologie Structurale (IBS), the ESRF, the ILL and the Grenoble Outstation of the European Molecular Biology Laboratory (EMBL). Associate members are pharmaceutical and biotechnology companies. The PSB is a unique collaboration that has the aim to determine the three- 
dimensional atomic structure of biological molecules such as proteins, in order to understand the function of these molecules in living cells and therefore to provide new approaches for the treatment of human diseases. Concerning the ESS (European Spallation Source) project, no new decisions have yet been taken. Although the project was not financed after evaluation in 2002, it, however, remains an important project for the future of neutron scattering in Europe. The discussion about such a source is continuing in different European countries.

The sources in Asia continue to deliver neutrons successfully, while in Australia the new ANSTO reactor OPAL (Open Pool Australian Light-water) is nearing completion. The construction of the Japanese JAERI-KEK Joint Facility for High Intensity Proton Accelerators, called the J-PARC Project, began in 2001. In 2004, the accelerator tunnel of the linac building as well as the accelerator tunnel of the $3 \mathrm{GeV}$ synchrotron building were completed and the fourth part of the $50 \mathrm{GeV}$ synchrotron tunnel was planned to be ordered. The first beams of this multi-disciplinary facility are expected in 2008.

The Spallation Neutron Source SNS is being built at Oak Ridge National Laboratory (USA). Ground breaking began in 1999 and the project was $80 \%$ complete in 2004 . The first neutrons are expected in 2006. The facility will provide the most intense neutron beams in the world and will become a leading research facility in studying the structure and dynamics of materials using neutrons. A Center for Nanophase Materials Science is being built close to SNS. The construction of other research institutes is also planned. The facility will have one target station and 24 instruments and will provide research opportunities for a broad range of scientific applications.

\section{Steiner, Chair}

\subsection{Commission on Powder Diffraction}

4.14.1. Newsletters. In 2004, the summer issue (No. 31), edited by N. Masciocchi, on Powder Diffraction of Molecular Functional Materials reached a record size of 75 pages presenting a variety of methods for solving complicated materials of general interest. The winter issue of 2004 (No. 32) was edited by R. Delhez. The popularity of the computer software pages by L. M. D. Cranswick is still very high. These pages are much appreciated by readers for their informative content and their effective presentation. News from ICDD and from IXAS are also present in all issues, together with news on forthcoming events. In an attempt to keep production costs as low as possible, the Newsletters are printed and distributed from Venezuela. Special thanks go to M. Delgado who voluntarily offered his help in this matter. The CPD is also grateful to the sponsors of the Newsletter who help cover the high printing and distribution costs.

4.14.2. Web site. The CPD web site is still the reference point for powder diffractionists around the world and has undergone a major reorganization. Besides links and information on events related to powder diffraction (including the CPD round robins), the web site gives free access to the CPD Newsletter archive, from which recent and past issues can be downloaded in pdf (Acrobat) format. The teaching section is still in its infancy and we strongly hope that more people will send in their contributions which would be for the benefit of everyone in the community.

4.14.3. Projects. The results of the round robin on size-strain line broadening that was conducted some time ago and a comparative analysis using three different line-broadening methods were published by D. Balzar, N. Audebrand, M. Daymond, A. N. Fitch, A. Hewat, J. I. Langford, A. Le Bail, D. Louër, O. Masson, C. N. McCowan, N. C. Popa, P. W. Stephens \& B. Toby: Size-Strain LineBroadening Analysis of the Ceria Round-Robin Sample [J. Appl.
Cryst. (2004), 37, 911-924]. By courtesy of the IUCr, the reprint will be again distributed with the current Newsletter (No. 32).

4.14.4. Textbook. The most ambitious current project of the CPD is a textbook entitled Powder Diffraction in Theory and Practice at a graduate level, which will be published by the Royal Society of Chemistry (London). Editors are the current Chair and S. Billinge from Michigan State University. Several members of the CPD have agreed to write chapters for this book.

4.14.5. Meetings/Workshops/Schools. In 2004, the Commission endorsed various meetings: Recent Advances in X-ray Powder Diffraction, 27 November-2 December 2004, Assiut, Egypt, organized by the Egyptian Society of Crystallography and its Applications (ESCA), EPDIC-9, European Powder Diffraction Conference, in Prague, Czech Republic, 2-5 September 2004, which was also the host for the yearly CPD meeting, and the Fifth Canadian Powder Diffraction Workshop (including neutron diffraction), 28-29 May 2004, at the University of Waterloo, Ontario, Canada. With W. I. F. David a member of the Programme Committee, the CPD was engaged in the planning of the powder sessions for the upcoming Florence Congress, ensuring that powder diffraction is well represented with nine Microsymposia and one Keynote Lecture. Under the auspices of the CPD, an international Workshop on Powder Diffraction at Non-ambient Conditions has been organized, which has attracted a great deal of interest. The Workshop will take place 5-7 October 2005 at the Max Planck Institute for Solid State Research in Stuttgart, Germany. The Commission also agreed to sponsor the regular Reynolds Cup.

\section{R. E. Dinnebier, Chair}

\subsection{Commission on Small-Angle Scattering}

4.15.1. Commission meetings and communication. Most of the Commission's communications were by means of e-mail correspondence. However, various members of the Commission were able to meet in connection with meetings and conferences around the world and had the opportunity to discuss the work of the Commission.

4.15.2. Activities. The main activities that took place in 2004 are: (1) The Commission (D. I. Svergun and J. S. Pedersen) updated the Commission's web pages for SAS-related links to other web pages on hardware and software. The material is placed on the Commission's web pages.

(2) The Commission has provided input on the topics of Symposiums for the Florence Congress. Suggestions for speakers and Chairs were given. The recommendations made by the Commission have largely been followed and have resulted in several SAS-related Microsymposia and a Keynote Lecture. Y. Amemiya and I. Torriani are involved in organizing a Microsymposium on Analysis of Anisotropic Materials.

(3) In connection with the Florence Congress, the Commission (J. S. Pedersen) is organizing a one-day tutorial Workshop on smallangle scattering. Several Commission members will give tutorial lectures so that a broad expertise is present at the Workshop.

(4) The Commission has again discussed initiating a round robin with inter-laboratory checks of calibration procedures for SAXS. There are still different opinions about the usefulness of such a task, which would be very time-consuming.

(5) The next International Conference on Small-Angle Scattering, SAS 2006, will be held in Japan. T. Hashimoto (University of Kyoto) will Chair SAS 2006. Commission member Y. Amemiya is on the Organizing Committee of SAS 2006; other members of the Commission are serving on the International Advisory Committee of SAS 
2006. The Commission will take responsibility for the SAS prizes (administration, funding and support for prizes) at future SAS conferences. G. Kostorz, a consultant of the Commission, will continue his efforts for the publication of the Proceedings for SAS 2006 in Journal of Applied Crystallography, as for previous Proceedings. This is strongly supported by the Commission. G. Kostorz has also offered his help with editing the Proceedings.

4.15.3. Educational activities. I. Torriani was involved in the organization of a School in Puebla, Mexico, in November 2004. It was one week of classes on principles and applications of synchrotron radiation, SAXS-WAXS instrumentation with emphasis on colloids, soft matter and polymers. The course was partially financed by the IUCr and organized by the Mexican Crystallographic Association.

P. Fratzl was a co-organizer of the 6th ELBA Max Planck Forum on Nanoscale Science and Technology Synchrotron Radiation and Nanobiosciences, Porto Conte, Sardinia (Alghero), Italy, 9-12 September 2004. He was also part of the Organizing Committee of the 4th European Winter School (NESY 2005) on Research with Neutron and Synchrotron Radiation, 7-12 March 2005, Sportheim Planneralm (Styria, Austria).

D. Svergun organized, together with R. Willumeit, GKSS, an EMBO Practical Course on Solution Scattering from Biological Macromolecules, EMBL Hamburg Outstation, 29 October5 November 2004. D. Svergun, Y. Amemiya and J. S. Pedersen presented lectures at the course.

J. S. Pedersen was part of the Organizing Committee of the 7 th European Summer School on Scattering Methods Applied to Soft Condensed Matter, Bombannes, Gironde, France, 5-12 June 2004. He also presented lectures at the School.

P. Thiyagarajan has presented a lecture entitled Overview of SAXS and SANS Applications in Biology at the SSRL Summer School, August 2004. He provided hands-on training: on the SAND instrument for 20 National School students at the 6th National School on Neutron and X-ray Scattering, Argonne National Laboratory, USA, August 2004 on SANS of block copolymer micellar solutions.

4.15.4. Community building activities. The members of the Commission are frequently invited to give scientific and tutorial talks on SAS techniques and their application and the members eagerly accept such invitations as such presentations help promote the technique. A complete list of such presentations will not be given in this report. However, it should in this connection be mentioned that D. Svergun is very active in promoting the SAS technique for structural investigation of biomacromolecular systems in solution. The following tutorial talks were given in 2004: Docking and SmallAngle X-ray Scattering studies, IPBS-CNRS Toulouse, France, 25 June 2004; Small-Angle Scattering Studies of the Structure of Biological Macromolecules in Solution, Institute of Crystallography, Moscow, Russia, 3 August 2004; Synchrotron Radiation Studies of the Structure of Biological Macromolecules at EMBL Hamburg. EMBL Predoctoral Course, Heidelberg, 11 October 2004.

P. Thiyagarajan has trained a number of young graduate students from various US universities and abroad in SANS and reflectivity experiments at IPNS and SAXS at APS. He continues to provide a SAS analysis software package to the students and faculty who visit IPNS and APS for experiments.

As responsible for the SAXS facility at the EMBL Outstation in Hamburg, D. Svergun has been involved in training a number of students and postdocs primarily from European Universities in the application of the SAS technique for biological solution scattering. D. Svergun is also offering his programs for analysis of SAS data to the community by making them publicly available at the EMBL home page.
J. S. Pedersen has during the last years built up a laboratory SAXS facility at the University of Aarhus, Denmark. The facility is used by a large number of researchers from the University of Aarhus, mainly from the iNANO Interdisciplinary Nanoscience Center and from the Department of Structural Molecular Biology. The instruments also attract a large number of collaborators from other Universities and Research Institutes in Denmark, Scandinavia and the rest of Europe. In the period 2002-2004, more that 30 different projects have been carried out. Consequently, a large number of students and postdocs have been trained in the SAS technique.

In 2004, A. Allen was invited to write a Feature Article on SmallAngle Scattering for Journal of the American Ceramic Society. The text is written with a 'ceramics' bias to complement recent SAS reviews in other areas. It is expected to appear in the July 2005 issue.

A. Allen has continued to work with J. Ilavsky and others at the Advanced Photon Source as they develop an increasingly large body of user analysis software (using IGOR macros) for SAXS data reduction and analysis. These are available from the APS UNICAT web site. For data reduction, this now encompasses USAXS, anisotropic USAXS, conventional 2D SAXS, anisotropic, anomalous and grazing-incidence SAXS, as well as high-energy SAXS. It also interfaces with the NIST SANS packages. For data analysis, this encompasses a large range of multicomponent form-factor shape and size distributions, interferences, fractal microstructures and 'unified model' hybrid microstructures. While independent of other current data format efforts, ultimate compatibility should be assured by the deep information-logging structure that has been incorporated into this development.

A. Allen has been involved in discussions of a proposal to construct a Bonse-Hart USANS instrument at the Spallation Neutron Source (SNS) in one of the SNS instrumentation review panels at Oak Ridge National Laboratory. It is his understanding that a revised full proposal for USANS to comprise part of a shared beamline at SNS will be considered further. However, no new USANS is currently planned for the refurbished High Flux reactor at Oak Ridge. Furthermore, the USANS at NIST is under pressure due to other instrument demands. Thus, he can report that, despite considerable advances in the development of USANS instruments in recent years, their scientific impact remains under considerable scrutiny. The SAS community should make clear how USANS instrumentation (or any other kind of SAS measurement) satisfies part of the overall SAS instrument portfolio. While the relatively low count rate and USANS $Q$-range upper limit do not allow a USANS instrument to replace a conventional SANS instrument as a general work-horse, unlike the case for USAXS, the USANS $Q$ range extends to the lowest $Q$ values of any SAXS or SANS method, except for non-specular reflectivity studies where other complications can apply. In this context, USANS provides significant 'added value' to the SAS community, and it needs to be available at least at the best or brightest neutron sources.

4.15.5. Consultant activities. P. Thiyagarajan and A. Allen have served as reviewers for the small-angle scattering section, three times a year, on the Proposal Review Panel for the Advanced Photon Source, Argonne National Laboratory, USA. P. Thiyagarajan also served on the National Institutes of Health.

A. Allen serves on the SANS Program Advisory Committee (PAC) for the NIST Center for Neutron Research. This panel reviews SANS proposals and allocates all general user SANS beam time.

A. Allen reports that some important trends can be discerned in the many SAXS and SANS user proposals submitted to the current leading USA X-ray and cold neutron user facilities. Both SANS- and 
SAXS-based researches in the USA are undergoing a period of rapid evolution and advance at the present time, with consequently increased demands to push the methods to their limits. For SANS, this is manifested in a demand for increasingly extreme sample environments (temperature, pressure, shear flow rate, magnetic field strength etc.); for SAXS, the growing importance of grazing-incidence geometry, fast time resolution, speckle techniques and anomalous SAXS is evident. The review panels, on which A. Allen and P. Thiyagarajan serve, provide feedback information for future SAS user research/instrument strategic planning at the facilities - formally in the case of the NIST SANS panel, more informally for the SAXS panel. A. Allen was asked to present the 'SAXS' case for high-energy X-ray physics at one of the APS strategic planning Workshops held in summer 2004. Finally, in connection with these activities, A. Allen is pleased to report a generally increasing rate of SAS publication in the USA.

J. S. Pedersen is a member of the review panel for beamtime applications within Soft Condensed Matter and Biological Materials at the ESRF, France. There are two proposal rounds per year. D. Svergun started to serve on this panel in 2005.

D. I. Svergun and J. S. Pedersen serve as reviewers at the GKSS Neutron Scattering Facility in Germany for proposals submitted through the EU programme ACCESS to Research Infrastructures.

4.15.6. Organizational activities. As mentioned previously in this report, Y. Amemiya is involved in the organization of the 13th International Conference on Small-Angle Scattering (SAS 2006). The conference will be held at Kyoto International Conference Hall, Japan, 9-13 July 2006. The following is an outline of SAS2006, which was made based on the discussion between the organizers and the Commission. The International Conference on SAS has been held every three (or four) years since 1965. In this conference, researchers in various scientific fields such as physics, chemistry, biology, materials science and engineering get together to discuss and explore the unique capabilities, needs and opportunities of SAS for structure determination of various systems from atomic or molecular to mesoscopic scales. Systems to be studied by SAS of X-rays and neutrons extend over quite a wide range: metals, ceramics, biomolecules, and soft matter such as polymers, liquid crystals, colloids, membranes and surfactants. Therefore, this conference is highly interdisciplinary in nature. In this conference, the organizers will attempt to bring speakers and participants in various fields to meet in the same conference rooms to present and discuss their SAS studies, as a common but most important keyword among others, beyond their special fields. The conference will highlight some topics on research; for example, research concerning: (1) dynamics and kinetics, (2) hierarchy structures studied with a wide range of momentum transfer, (3) novel techniques concerned with optics, detectors, microbeam and contrast variation, (4) experiments under extreme ambient conditions, and (5) open-non-equilibrium systems under various external fields. In addition, as this is the first opportunity for an SAS conference to be held in Asia, the organizers wish to take advantage of this opportunity to promote SAS activities in the Asian and Oceanic region as well as in Japan. The number of expected participants is about 400 . The organizers encourage all researchers related with the IUCr to participate in SAS 2006 in Kyoto. The organizers hope that they will be able to have financial support from the IUCr as was the case in previous SAS conferences. Detailed information is available at http://sas2006.scphys.kyoto-u. ac.jp/ (Chair of Organizing Committee T. Hashimoto, Vice-Chair N. Yagi; Chair of Programme Committee Y. Amemiya; Chair of Local Executive Committee K. Osamura; Chair of Editorial Committee M. Shibayama).
I. Torriani is organizing a Symposium to take place in February 2005 , on the structure of polymers and interaction with industry, as a satellite to the users meeting of the National Synchrotron Laboratory.

D. Svergun has been coordinator of the Design Study called SAXIER (involving EMBL, Soleil, ESRF, Elettra, Daresbury), which is currently under negotiation with the EU.

P. Thiyagarajan has been co-organizer of the sessions at the ACA meeting at Orlando in May 2005: 10.03 Novel Instrumental Development in Scattering and Reflectivity; 10.04: Applications of SAXS and SANS to Biological Systems; and Workshop on Biology on the Colloid to Nanoscale.

4.15.7. Technical activities. A new wiggler has been installed at the LNLS synchrotron and, as soon as the synchrotron starts operating in May 2005, I. Torriani will be involved in starting the commissioning of the new SAXS beamline, which will be completed during 2005.

D. Svergun has been responsible for a major upgrade of the X33 SAXS beamline at EMBL Hamburg in 2004. A proposal for the BioSAXS beamline at Petra-III (DESY, Hamburg) has also been submitted.

A. Allen has during 2004 continued to explore the potential for developing a NIST Standard Reference Material (SRM) for SAS intensity calibration, particularly for SAXS. As far as I can judge, several tens of 'table-top' SAXS instruments are being supplied and sold per year by companies such as Bruker-AXS and others. In this context, a NIST SRM would provide the end users of such instruments with a calibration standard sample and a NIST-certified calibration curve for the measured SAXS intensity over much of the $Q$ range accessible to such instruments. A candidate calibration material has been identified and there have now been several years of multi-instrument experience at the Advanced Photon Source. The calibration curves for individual samples would be measured using the NIST-built USAXS instrument at UNICAT, which uses 'primary' calibration methods and does not, itself, need a scattering or attenuator standard. However, full economic cost recovery is required and much remains to be done to build the case for such a NIST SRM.

\section{J. S. Pedersen, Chair}

\subsection{Commission on Structural Chemistry}

Activities were mostly concentrated on developing a strong programme in the area of structural chemistry for the upcoming Florence Congress. The Commission sought input on topics for Microsymposia, potential Symposia organizers/Chairs and on Keynote speakers by e-mail from its own membership and from a wide range of scientists around the world with interests in all aspects of structural chemistry. The response was excellent and the Commission through its representation on the Programme Committee was able to assemble a very strong programme that will run continuously through the Congress, covering topics including design and synthesis of crystalline materials, intermolecular interactions and crystal packing, functional crystalline materials, chemical reactions in crystals, topology of crystalline networks, study of crystals under non-ambient conditions, and spectroscopic as well as various crystallographic methods. Symposia on drug design, catalysis and supramolecular chemistry are also included.

The Commission endorsed the next in the series of highly successful Indaba meetings, Indaba-V, to be held in Kruger National Park, South Africa in 2006. The principal organizer is Commission member D. C. Levendis. The Commission also endorsed, together with the Commission on Crystal Growth and Characterization of 
Materials, a proposed full-day Workshop on Small Molecule Crystallization to be organized in conjunction with the Florence Congress.

Commission members D. Braga and L. Brammer were among the Organizing/Programme Committee of the CrystEngComm Discussion 2 meeting held in Nottingham, UK, in September 2004. The meeting brought together a multidisciplinary group of scientists and many students working in the area of crystal engineering. Presented papers were also published in the RSC journal CrystEngComm.

L. Brammer, Chair

\subsection{Commission on Synchrotron Radiation}

The mission of the Commission is to promote access of crystallographers worldwide to the world's synchrotron-radiation facilities. A sub-charge is to promote the development of crystallographic instrumentation technology and standards, particularly in the direction of X-ray detectors. To foster communication, we endorse international meetings as the best means to achieve these goals.

We therefore sent a letter to E. E. Vogel, Departamento de Ciencias Fisicas, Universidad de La Frontera, Temuco, Chile, to support the application for IUCr support of the Latin-American Workshop on Magnetism, Magnetic Materials and their Applications that he was organizing. This meeting included many speakers using synchrotron-radiation (SR) methods on its agenda both in the programme and in the list of invited speakers. The organizers were encouraged to contact the LNLS facility in Campinas, Brazil, which is active in hosting users of SR and is building a base of South American users. J. Brum, director of LNLS, also provided support.

In anticipation of the Florence Congress, we nominated R. Felici of ESRF, France, to attend the planning meeting and to promote the appearance of SR speakers and symposia in the programme. He was very successful in this mission and we can all look forward to an exciting Congress.

Another Special Issue of $J S R$ on X-ray detectors is in preparation. So far, 10 contributions have been received and are in the refereeing process. The issue is expected to be completed by the end of 2005 .

The Commission was represented at the detector Workshop, which was part of the Advanced Photon Source (APS) user's meeting, 6 May 2004. J. Quintana introduced the Workshop by reminding attendees that there is often a wide gap between the knowledge and experience of beamline users and the technologies that are available. He considers this to be a major obstacle to progress in the development of SR methods. This is precisely why the Commission is trying to communicate with IUCr members about technological advances.

At the Workshop, J. Wang presented an overview of detector technologies and described how the APS 'detector pool' operates. S. Ross described the advances made to develop avalanche photodiode (APD) detectors. Apart from the difficulty of obtaining the devices, they appear to be attractive for their moderately high energy resolution and good time resolution: when used with a suitable gated integrator, they should be able to pick out individual pulses from the 1296 bunch mode of APS, corresponding to a 2.8 ns spacing.

E. Westbrooke described his recent developments of detectors for protein crystallography (PX) at the Berkeley-based 'Molecular Biology Consortium'. Collaborating with Optics1 Inc., he presented promising development work on lens coupling of a CCD to a phosphor. One advantage is that it allows overlap of the borders between the 'tiles' of the multi-CCD arrays. It will be interesting to see if his technology will be superior to earlier attempts that suffered from degradation of the optical surfaces with time. He also described two emerging technologies: the JPL hybrid imaging technology (HIT) which uses 'bump bonding' of CMOS electronics to a conventional CCD sensor array and the $3 \mathrm{DX}$ concept of S. Parker (Hawaii) involving micro-machining of Si sensor blocks with poly-Si electrodes drilled into them to form a new type of pixel array.

G. Darbyshire gave a full account of the detectors being developed for the Diamond Light Source, UK, which demonstrated that the new facility takes detectors very seriously. He advocated different short-, medium- and long-term solutions for each technique to be served. Crystallography users would have available new 'diffex' strip detectors for powder diffraction with customized energy resolution on each channel and a very large number of channels available simultaneously. In the long run, PX would be served by Monolithic Active Pixel Sensor (MAPS) arrays, which are currently being developed in a $3 \mathrm{~K} \times 4 \mathrm{~K}$ format with $5 \mu \mathrm{m}$ pixels. These are based entirely on $\mathrm{CMOS}$, including the sensor itself, so will be easy to mass produce. He expects MAPS to replace current CCD technology eventually.

\section{Robinson, Chair}

\subsection{Commission on XAFS}

The Commission continued with D. Arvanitis as Chair after the Geneva Congress in August 2002. Owing to the long-term lack of activities of the Commission, the Executive Committee decided to appoint A. M. Molenbroek as Chair from 1 October 2004. It turned out that both R. F. Pettifer and K. Baberschke had resigned from the Commission, so from October 2004 the Commission members have been D. Arvanitis, K. Asakura, B. Hedman, A. Michalowicz, S. Mobilio, A. M. Molenbroek (Chair) and S. S. Hasnain (Consultant). Contacts have been initiated and maintained among the members mainly via e-mail. At a meeting at the Florence Congress the future goals and plans of this Commission will be agreed. B. Hedman is a member of the Scientific Programme Committee of the Florence Congress.

The main goals until now have been:

- To suggest active and qualified members for the future Commission, to be appointed at the Florence General Assembly. It turned out that the responses to whether or not this Commission should continue were so positive that a higher level of activity can be expected from now on.

- To help organize a Microsymposium on XAFS at the Florence Congress. S. Mobilio and J. Garcia-Ruiz will Chair a session on Combined XAS and XRD Techniques in Physics, Chemistry and Material Science.

Contacts to the IXS (International XAFS Society) will be tightened. A strong presence at the next International Conference on X-ray Absorption Fine Structure (XAFS XIII), which will be held in 2006 at SSRL in Stanford, California, USA, will be a good opportunity for this. B. Hedman is both a member of the IXS Executive Committee and Co-Chair of XAFS XIII.

\section{A. Molenbroek, Chair}

\section{Sub-committee on the Union Calendar}

The Sub-committee receives and considers requests for IUCr sponsorship and nominal financial support and makes recommendations to the Executive Committee. Acting on the recommendations made by the Sub-committee, during 2004 the Executive Committee approved sponsorship of various Schools and meetings, mostly with financial support. Those held in 2004 are listed at the beginning of this Report of the Executive Committee. Those scheduled for 2005, but approved in 2004, are listed below: 
International School on Crystal Growth: Fundamentals, Methods and Applications to Biological and Nano Crystals, Puebla, Mexico, 7-11 March 2005.

BCA/CCG 10th Intensive Course in X-ray Structure Analysis, Durham, UK, 4-11 April 2005.

RapiData 2005, Brookhaven, USA, 10-15 April 2005.

Evolving Methods for Macromolecular Crystallography, Erice, Italy, 19-29 May 2005.

Nancy 2005 International School on Mathematical and Theoretical Crystallography, Nancy, France, 20-24 June 2005.

XVII International School on Physics and Chemistry of Condensed Matter and V International Symposium on Physics in Material Science: Materials in Transition, Bialowieza, Poland, 21-29 June 2005.

Organizers of meetings wishing to seek IUCr sponsorship should submit applications at least nine months in advance of the meeting, writing to the Chair of the Sub-committee. The present Chair is Professor M. A. Carrondo. For up-to-date contact information, application procedures and rules, see http://www.iucr.org/iucr-top/ iucr/calendar.html.

Applications for sponsorship of satellite meetings require the approval of the Chair of the Organizing Committee of the main meeting. Meetings (other than satellite meetings) scheduled to be held within two months before or after an IUCr Congress will not be considered for sponsorship. For any meetings scheduled to be held between two and three months before or after a Congress, the application for sponsorship will be sent to the Chair of the Congress Programme Committee for approval, or otherwise. Meetings (other than satellite meetings) scheduled to be held, in the respective region, within two months before or after a meeting of a Regional Associate will not be considered for sponsorship unless the application has received the approval of the Chair of the Programme Committee of the Regional Associate meeting.

The IUCr continues to support and uphold ICSU's policy of nondiscrimination and adheres to its decisions and procedures concerning the free circulation of scientists. Organizers of any meetings seeking IUCr sponsorship or support must assure the Calendar Sub-committee that the authorities of the country in which the meeting is to take place guarantee free entrance of bona fide scientists from all countries.

\section{Sub-committee on Electronic Publishing, Dissemination and Storage of Information (CEP)}

\subsection{Meeting attendance}

In 2004, members of the CEP attended the following meetings:

H. D. Flack attended the third Workshop on the Open Archives Initiative (OAI3), CERN, Geneva, Switzerland, 12-14 February 2004, where he was an invited participant at the discussion panel on 14 February.

H. D. Flack visited the IUCr editorial offices in Chester, UK, 18-20 October 2004.

The meeting attendances of the CODATA and ICSTI representatives, whose work is so closely related to that of the CEP, are recorded in their individual reports.

\subsection{Information services}

The CEP has continued its task as editorial body for the online information services of the IUCr. The task of day-to-day maintenance of Crystallography Online is performed under the responsibility of S. Parsons. Y. Epelboin continues his good work on the maintenance of the list of software of interest for crystallography. The voluntarily maintained mirror sites within the existing system have now been phased out. Owing to the heavy workload in the editorial offices in Chester, further progress on re-engineering the IUCr web site and introducing more centralized web services has been slower than hoped. Such developments now have high priority. The current IUCr web site appears old-fashioned and will benefit from improved navigation.

\subsection{Crystallography Journals Online}

On the 10th December 2003, the Science and Technology Committee of the United Kingdom House of Commons (UK national parliament) issued invitations for evidence to support its inquiry into scientific publications. M. H. Dacombe, J. R. Helliwell, H. D. Flack, P. R. Strickland and B. McMahon submitted written evidence to the Committee on 9 February 2004 on behalf of the IUCr; this document was entitled Publishing Crystallography Journals in the Electronic Environment: the Experience of a Specialist Learned-Society Publisher. The report highlighted that real value to scientific literature has enormously increased in the past decade through technical innovations and that the IUCr has worked hard to provide added value in the field of crystallography. It was stressed that finite acquisition budgets may leave libraries unable to afford IUCr journals and that any economic restructuring of the scientific journals market (e.g. to promote open access) must guarantee its quality and longevity. Further for the assessment, selection and improvement of the content of scientific articles it was considered that peer review must remain paramount in future developments of scientific journals. The problem of the preservation and archiving of primary journals published in electronic format was also highlighted.

\subsection{World Directory of Crystallographers}

In spite of the use of the online interface to WDC 11 to update entries on individuals, the coverage and completeness of WDC 11 remains unsatisfactory. At present, $W D C$ is not integrated with the journals electronic submission procedure, which would ensure more regular and reliable updating. Yet more publicity is necessary to encourage crystallographers to keep their own record up to date. Unfortunately, spam, 'phishing' and other abuses of openly available contact information act as a major discouragement for making personal data available online or otherwise.

\subsection{NeXus CD-ROM}

Under the continued leadership of L. M. D. Cranswick, individual NeXus CD-ROMs were made on request, no general release being made in 2004. An arrangement has been found for the manufacture and distribution of the CD-ROMs in collaboration with CCP14 in Birkbeck College/University College, London, UK. The CD-ROM is made available to laboratories and scientists with an interest in crystallography lacking adequate connection to the internet. The CDROMs contain public domain software and copies of web sites of interest to crystallographers.

\subsection{Open access}

The CEP is particularly attentive to developments in the scientific community at large concerned with access to scientific literature and data. The CEP devoted considerable time and effort in the management of open-access initiatives related to crystallographic publications and data. This activity resulted in the production of position papers on open access and the subsequent introduction in 
January 2004 of an open-access option for contributors to IUCr journals on the principle of the 'author-pays' model. The IUCr applied and won funding for a one-year contract to allow papers submitted from authors in the UK to become open access. [This funding was subsequently renewed for a second year.] The CEP has been collaborating with the e-Bank project involving the UK National Crystallography Service at Southampton University. This project provides access to experimental records and observations associated with crystal structure determinations carried out by the Service. It provides original data suitable for harvesting by databases and linking from publications and aims also to place in the public domain scientific results that do not find their way into formal published literature. The involvement of the CEP has included advice and suggestions for handling the management of intellectual property rights, descriptive metadata allowing the operation of added-value service providers, and mechanisms for validating and assessing the quality of individual data sets. The CEP is also trying to highlight the importance of standard metadata describing scientific result sets within CODATA and in the STM publishing arena. This is one of a small but growing number of initiatives to provide data repositories and bridge the gap between data processing and publication for routine structures, a development that the IUCr is following with attention. The CEP has also been involved (through the Chester editorial office) in a collaboration with P. Murray-Rust of Cambridge University, UK, to derive chemical representations of molecules from published crystal structures, an initiative that also has relevance for the work of COMCIFS in developing formal descriptions of chemical properties.

\subsection{International Tables}

Activity was commenced principally in the editorial office around the specification of new business and functional models for electronic versions of the information contained in International Tables for Crystallography. This has included the development of some pilot prototypical applications and the testing of some ideas in the production of the CD-ROM accompanying the printed edition of Volume G of International Tables. Subsequently, a separate working group was appointed by the Executive Committee to deal with the specific needs of 'International Tables for Crystallography Online', effectively removing this area of activity from the mandate of the CEP.

H. D. Flack, Chair

\section{Committee for the Maintenance of the Crystallographic Information File Standard (COMCIFS)}

COMCIFS is a Committee appointed by the Executive Committee of the IUCr. It is charged with the supervision of the Union's Crystallographic Information File (CIF) project. The current members of COMCIFS are: I. D. Brown (Chair), H. M. Berman, H. J. Bernstein, R. W. Grosse-Kunstleve, S. R. Hall, G. Madariaga, B. McMahon and J. D. Westbrook. Except for meetings held during the IUCr General Assemblies, COMCIFS conducts all its business by e-mail.

This year COMCIFS has put considerable energy into the publication of Volume G of International Tables for Crystallography, the volume that will contain a comprehensive account of the CIF project. The deadline for the receipt of copy was at the end of 2003. Since then the Editors and the Chester Office have been working hard to ensure uniformity of presentation and the authors have been checking the proofs in time for publication in 2005. Checking the proofs has led to the discovery of minor changes that are needed in some of the CIF dictionaries. A revised version of the image CIF dictionary used for recording two-dimensional diffraction images is expected to be approved during the coming year.

The IUCr editorial office has, with advice from B. Toby, been developing a new set of web pages offering guidelines and powder CIF (pdCIF) template files for authors who submit powder diffraction data and Rietveld refinement results as part of an article for an IUCr journal, with the aim of encouraging authors to provide data in pdCIF format and to include as much information as possible in their pdCIFs. Mike Hoyland of the IUCr office has modified checkcif to run tests appropriate to powder data.

The IUCr is also planning to make the series International Tables for Crystallography available online and is planning to add features that may include the ability to access and download symmetry data in CIF format. This is likely to result in (or require) the development of a new and enlarged version of the symmetry CIF dictionary.

As mentioned in last year's report, after fifteen years the coreCIF dictionary is in the process of a major revision. A number of the simpler changes were approved at the end of 2003 as version 2.3, but during 2004 the Core Dictionary Maintenance Group has been struggling with the challenge of encoding descriptions of molecules, extended scattering density and twinning. Exploring the different ways in which the chemical and crystallographic descriptions of a molecule can be linked has raised some fundamental questions about the methods of linking information that can only be resolved when we know the direction in which CIF will develop in the future. Information technology has seen major changes since the IUCr adopted CIF in 1990 and COMCIFS now needs to plan carefully for the rational development of CIF over the next decade.

One of the goals of COMCIFS is to discourage the formation of CIF dialects, but technical necessities have forced the development of two somewhat divergent Dictionary Definition Languages (DDL), DDL1 being used for the small-cell coreCIF dictionary and DDL2 being used for the large-cell mmCIF dictionary. Some software developed for manipulating mmCIFs cannot read those written with the coreCIF dictionary and vice versa. It is, however, feasible to create software that works with both DDL1 and DDL2 (viz CIFtbx and the CBFlib-derived parser in Rasmol). Since the interface between the small- and large-cell structures is becoming an increasingly important area of study, COMCIFS needs to explore how these two standards can be made to converge.

Another problem of concern to COMCIFS is the lack of opensource CIF software tools, particularly as the wide range of available XML tools makes XML an attractive alternative. The IUCr is making some effort to promote the development of standards-based opensource utilities and each year sees a few more independently developed applications added to the collection. Work is under way by $\mathrm{H}$. J. Bernstein at Dowling College, USA, under contract to the IUCr, to upgrade some of the software used by the IUCr in its publication process to be compatible with the CIF 1.1 specification and with both DDL1 and DDL2. This software will be discussed at the Florence Congress and will be made available as open-source software to encourage other software developers to make their software able to deal with both DDL1 and DDL2. The year has also seen the publication of other programs such as pdCIFplot, written by B. Toby, designed for refereeing Rietveld refinements, but also useful as a graphical browser of powder diffraction data stored in pdCIFs. Two CIF browser-editors have also been released: enCIFer by the Cambridge Crystallographic Data Centre and CIFEDIT by B. Toby. These applications read in the version of the dictionary that was used to create the CIF, putting the user just a mouse-click away from all the 
dictionary information about any item in the CIF. Further, CIFEDIT is able to handle dictionaries written in both DDL1 and DDL2. These browser-editors not only make it easier to create and manipulate CIFs, but by reading in the appropriate dictionary they do not have to be modified every time a new version of a dictionary appears. Many of the frustrations of maintaining software would disappear if all applications made use of the machine-readability of CIF dictionaries.

While the CIF standard is now widely adopted by the crystallographic community, extending it and keeping it up to date requires considerable effort. COMCIFS is much indebted to the many volunteers who contribute to this work and who help to chart the future course of CIF.

\section{D. Brown, Chair}

\section{Committee on Crystallographic Databases}

All of the crystallographic databases continued to develop rapidly during 2004. By the end of the year, the total number of structures recorded in the PDB, NDB, CSD, ICSD and CRYSTMET had exceeded 530,000, with an overall accession rate of more than 40,000 new structures expected during 2005. The PDB, in particular, continues to show rapid growth, with a further 5,360 experimental structure determinations added during the year. The largest of the databases, the CSD, recorded nearly 29,000 new accessions, and the CSD system was expanded through the inclusion of Mogul 1.0, a knowledge base of intramolecular geometry containing some 21 million bond lengths, angles and torsions. Deployment of the PDB via the web continues to develop and improve. CCDC staff were invited to meet with the IUCr Executive Committee and discuss CSD provision to academics worldwide (now numbering 65), with special emphasis on provision to developing countries. It is pleasing to note that a number of papers in the Special Issue of Acta Crystallographica Section B (jointly with Section D), devoted to crystallographic databases, and prepared by members of this Committee, have shown some very high citation rates during the three years since its publication in June 2002.

\section{F. H. Allen, Chair}

\section{IUCr Newsletter}

Four issues of the IUCr Newsletter were distributed in 2004 (Volume 11 No. 4, Volume 12 Nos. 1, 2 and 3). By the end of the year, Volume 12 No. 4 was at the printer and Volume 13 No. 1 was in preparation. Volume 11 No. 4 was described in the 2003 year-end report. This report will cover all four issues of Volume 12. All these issues were 32 pages in length with a preview of the XX IUCr Congress in Florence presented in issue No. 2. The second circular for the Congress was included as a 24 page pullout in issue No. 3. As in previous years, the content covered activities of the IUCr and its Regional Associates, Letters to the Editor, news concerning crystallographers and crystallography in general, awards, elections, resources, obituaries, meeting reports, future meeting announcements, and a general meeting calendar.

Each issue carried a President's column and three of the four issues had guest editorials (H. Fuess wrote about the European Crystallographic Association, Y. Osipyan introduced the articles on crystallography in Russia and J. M. Guss discussed scientific publishing in the 21st century as a prelude to the launch of Acta F). Volume 12 No.
4 included the IUCr Executive Committee Report of the Meeting in Budapest (August, 2004).

Each issue devoted two pages to brief summaries of selected articles recently published in IUCr journals. The articles on crystallography in the various countries adhering to the Union continued with Crystallography in Italy, edited by D. Viterbo, in Volume 12 No. 1 and Crystallography in Russia, edited by L. A. Aslanov, appearing in Volumes 12 Nos. 2 and 4.

Reports were published covering meetings in Singapore, Germany, Brazil, Uruguay, Poland, Morocco, India, Turkey, Slovenia and Hungary. Two issues carried reports covering the ECM-22 meeting in Budapest, Volume 12 No. 3 carried a special review on '50 Years of Collagen Triple Helix: a Celebration of Science - a Tribute to G. N. Ramachandran'.

The mailing list was 5\% larger than in 2003 with an average distribution of 16,245. Twenty-two countries (up from 19 in 2002) now assist in the effective and economic distribution of the Newsletter. The individual distribution is sent to 81 additional countries, with 26 countries currently receiving fewer than five copies of the Newsletter. Sustained advertising volume coupled with efficient production kept the cost to the IUCr below USD 25,000 for the year. (Distributors: F. Hamzaoui, Algeria; B. W. Skelton, Australia; J. Valderrama-N., Colombia; B. Kojic-Prodic, Croatia; A. Gomez, Cuba; J. Hasek, Czech Republic; C. Lecomte, France; Executive Secretary and A. Nangia, India; P. Spadon, Italy: Ismunandar, Indonesia; A. Satomi, Japan; A. H. Othman, Malaysia; Honorary General Secretary, New Zealand; J. Lipkowski, Poland; M. Costa, Portugal; J. Vittal, Singapore; L. Nassimbeni, South Africa; H. Grimmer, Switzerland; Yu Wang, Taiwan; K. Haller, Thailand; R. Olthof-Hazekamp, The Netherlands; G. Diaz De Delgado, Venezuela.)

\section{J. L. Flippen-Anderson, Editor}

\section{IUCr/Oxford University Press (OUP) Book Series}

The Book Series Committee continued its activities during 2004. In the series IUCr Monographs on Crystallography, the following three books have been published:

Crystallography of Modular Materials by G. Ferraris, E. Makovicky and S. Merlino.

Diffuse X-ray Scattering and Models of Disorder by T. R. Welberry. Crystallography of the Polymethylene Chain - an Inquiry into the Structure of Waxes by D. L. Dorset.

A few books are under consideration or in the production phase and there are contacts with other authors who are preparing proposals to be reviewed by the Committee and OUP. A productive meeting between the Chair and the science editor of OUP took place at the ECM in Budapest, Hungary. Prospective authors are encouraged to contact the Chair of the Committee (schenk@science.uva.nl), as are people who may suggest topics and authors. Manuscripts covering important aspects of crystallography and related fields are most welcome.

H. Schenk, Chair of Book Series Committee

\section{Regional Associates and Scientific Associates}

\subsection{American Crystallographic Association (ACA)}

The ACA continued its enterprise of actively serving and expanding the interaction among the members of the crystallographic community in North America as a Regional Associate of the IUCr. In 
2004, the ACA also established a new category of membership, the Latin American Country Membership. Letters containing the rules, requirements and benefits of the membership were sent to the National Committees of all the countries in Central America, South America and Mexico, inviting them to join the ACA.

The 2004 Annual Meeting was organized in Chicago, Illinois. This meeting had a record attendance of 1,213 participants. Four Workshops were organized, including one special visit to the APS/IPNS synchrotron facilities. 32 parallel sessions were organized by the Special Interest Groups and 272 poster contributions were presented during three poster sessions. The Transactions Symposium dealt with the topic Crystals in Supramolecular Chemistry. The Fankuchen Award was presented to A. McPherson and the Trueblood Award was presented to R. E. Marsh. The Margaret C. Etter Early Career Award was granted to L. MacGillivray.

A ten-day intensive summer course was organized at Indiana University of Pennsylvania by B. M. Craven and C. H. Lake. The course was dedicated to young crystallographers interested in learning theory and practice of single-crystal and powder diffraction. Candidates from the USA and several Latin American countries were awarded scholarships.

\section{L. Torriani, IUCr Representative}

\subsection{Asian Crystallographic Association (AsCA)}

At the tenth Council meeting of AsCA held on 10 August 2002, during the Geneva Congress, the issue of the timing of the election of the office bearers of AsCA, discussed earlier in the 9th Council meeting at Bangalore, India, was settled. It was decided that the office bearers would henceforth be elected at the Council meeting held during triennial AsCA meetings instead of those held during the IUCr Congresses. The constitution was appropriately amended. The Council elected the following Office Bearers: President Y. Wang, Vice-President M. Vijayan, Secretary/Treasurer B. Skelton. They would serve until the 2004 meeting of AsCA. The Council confirmed Hong Kong, People's Republic of China, as the venue for the 2004 meeting with I. D. Williams as the Chair of the Organizing Committee and M. Sakata as the Chair of the Programme Committee.

In pursuance of the decision of the 9th Council meeting at Bangalore in 2001 to hold joint meetings of AsCA and national crystallographic societies in the region in the years when regular triennial AsCA meetings and IUCr Congresses do not take place, the first such meeting jointly sponsored by AsCA and the Society of Crystallographers in Australia and New Zealand (SCANZ) took place 10-13 August 2003 in Broome, Western Australia. The meeting was attended by 240 full registrants, 60 student registrants and 40 accompanying members. The IUCr was represented by its President, W. L. Duax. 15 travel scholarships were awarded to Australian students by SCANZ while 15 were awarded using IUCr support to young scientists from other parts of the region. The conference consisted of 6 plenary talks, 56 oral presentations, 136 poster presentations and 3 specialized Workshops. The preparations for the Hong Kong AsCA meeting were reported in the 11th Council meeting held in Broome on 12 August 2003. It was decided that the next joint meeting would be held in Japan in 2006 in association with the Crystallographic Society of Japan.

AsCA '04 was held in Hong Kong, 27-30 June 2004. There were more than 300 registered participants including young scientists supported by the IUCr and Rigaku. There were six Plenary Lectures, 70 oral presentations distributed over 15 Microsymposia and about 200 poster presentations. The IUCr was again represented by W. L. Duax. The 12th Council meeting took place on 29 June 2004. The following office bearers were elected for the next triennium: President M. Vijayan, Vice-President J. M. Guss, Secretary/Treasurer I. Williams. S. R. Hall, the Trustee, reported that the financial position of AsCA was healthy. It was confirmed that the joint meeting of AsCA and the Crystallographic Society of Japan would be held at Tsukuba in November 2006. The proposal to hold the triennial meeting in Taiwan in 2007 was accepted.

\section{Y. Ohashi, IUCr Representative}

\subsection{European Crystallographic Association (ECA)}

In 2004, the most important activity was the 22nd European Crystallographic Meeting, ECM-22, held in Budapest, Hungary, 26-31 August 2004, with A. Kálmán as Chair of the Organizing and of the Programme Committees. The programme included 16 Keynote Lectures and 40 Microsymposia, with a total of 203 oral presentations and two poster sessions, and about 400 abstracts. The registered participants were more than 600. A satellite meeting on Crystallography at the Start of the 21st Century: Mathematical and Symmetry Aspects was held before the ECM. The ECA Council and Executive Committee met in Budapest and several important decisions were taken. The membership application from Algeria was approved, while contacts with Tunisia continued and preliminary contacts with Belarus and Moldova were established. The return of Ukraine into the ECA was welcomed and that of Bulgaria encouraged. Reports of the activities of the 13 SIGs were presented. A permanent contribution by ECA in the IUCr Newsletter was arranged. L. Van Meervelt gave a detailed description of the arrangements for ECM-23 (http://www.ecm23.be) to be held in Leuven, Belgium, 6-11 August 2006. Preliminary steps for the organization of ECM-24 (26-31 August 2007; http://www.ucam.ac.ma/ fssm/ecm24/) in Marrakesh, Morocco, were discussed with A. Thalal.

The Executive Committee decided to give the ECA Prize the name of Max Perutz and in Budapest the first Max Perutz Prize was conferred on G. M. Sheldrick of the University of Göttingen, Germany, 'for seminal contributions to the development of direct methods and for converting the theory into straightforward procedures for solving small and large crystal structures'. After the meeting in Budapest, the main activity was concerned with the preparation of the ECA participation in the Florence Congress, where meetings of the ECA Council and Executive Committee have been arranged.

\section{Viterbo, IUCr Representative}

\subsection{International Organization of Crystal Growth (IOCG)}

During 2004, the International Organization of Crystal Growth focused its activity on the organization of the triennial Congress that took place in Grenoble, France, 9-13 August 2004 (http:// iccg14.inpg.fr) and the triennial Summer School on Crystal Growth that was held in Berlin, Germany, 1-8 August (http://isscg12. ikz-berlin.de/index.phtml). Several members and consultants of different IUCr Commissions were involved in both events as main organizers, lecturers or session Chairs.

During the Executive Committee meeting in Grenoble, G. Stringfellow presented an update of plans to host ICCG-15 in Salt Lake City, Utah, USA, 5-10 August 2007 with G. Stringfellow and R. Feigelson as Co-Chairs. The associated ISSCG-13 is planned to be held the previous week in nearby Park City, Utah, with C. Wang and J. De Yoreo as Co-Chairs. The Council approved these plans for ICCG15 and ISSCG-13. At the same meeting, an IOCG policy of not endorsing international conferences that compete with ICCG and 
ISSCG meetings was discussed. A policy of not endorsing competing international crystal growth conferences or Schools that are held during the period 6 months before and 4 months after an ICCG was approved.

Elected Officers and Executive Committee Members of the IOCG (2004-2007): President R. F. Sekerka (USA), Vice-Presidents J. P. Van der Eerden (The Netherlands) and T. Ohachi (Japan), Secretary T. F. Kuech (USA), Treasurer T. Duffar (France), Past President T. Nishinaga (Japan), Honorary Principal Founder IOCG M. Schieber (Israel); Executive Committee (eight members elected for 20042007): G. Mueller (Germany), J. N. Sherwood (UK), K. Kakimoto (Japan), J. Derby (USA), R. Fornari (Germany), Jiang Min-Hua (China), E. Zharikov (Russia) (replacing V. Osiko who declined to serve), M. Heuken (Germany).

As usual, several prizes were awarded to outstanding scientists for their contribution to the development of crystal growth theory and technology. The prizes were awarded during a ceremony at the ICCG banquet on 12 August, 2004.

The 2004 IOCG Frank Prize was awarded to G. Comsa, Institut für Physikalische und Theoretische Chemie der Universität Bonn, Germany, for quantitative studies of crystal growth far from equilibrium.

The 2004 IOCG Laudise Prize was awarded to T. Nishinaga, President, Toyohashi University of Technology, Toyohashi, Japan, for research on epitaxic growth of semiconductors.

The 2004 Schieber Prize was awarded to J. Boniakowski, Groupe de Physique des Solides, Paris, France, for his work on electronic and energetic trends for transition metals adsorbed on large gap oxides.

The President and Executive Committee of IOCG worked hard in order to improve the visibility of this organization inside and outside the community of crystal growers. The first result of this activity is represented by the new web site (http://www.iocg.org/), which provides useful information about the organization, its Officers and its history as well a number of useful links to national crystal growth organizations. A new logo was selected during the conference at Grenoble.

\section{R. Fornari, IUCr Representative}

\subsection{International Centre for Diffraction Data}

As in previous years, R. L. Snyder represented the ICDD at the meetings of the Commission on Powder Diffraction, and now also the IXAS. A main target of the Commission is to keep up the active collaborations and good relationships with these organizations.

R. E. Dinnebier, IUCr Representative

\section{Representatives on Other Bodies}

\subsection{IUPAC Interdivisional Committee on Terminology, Nomen- clature and Symbols (ICTNS)}

Reinvigorated by J. Lorimer's appointment last year as the new Chair of ICTNS, vigorous discussion of many nomenclature reports submitted throughout the year was engaged in by members. Most reports emanated from IUPAC divisions; 14 in all were finally accepted. Requests to review such reports are now sent to all members by IUPAC's 'ManuscriptCentral'. Among matters of interest to the IUCr is the question of whether to insert a space or not between numerical values and their unit symbol, e.g. between ' 2.5 ' and ' $\mathrm{A}$ ' or between a value and its uncertainty within parentheses. The current ISO standard 31-0 requires a thin (half) space; however, the draft ISO/IEC 80000 follows CODATA style and has no space. A choice may have been reached at the last meeting of the Comite Consultatif des Unités (CCU). Another proposal concerned the use of the name 'uno', symbol U, for the unit one so that dimensionless numbers may be treated in the same way as all other SI units. Thus, a second phase in a material detected at a $15 \mu \mathrm{g} / \mathrm{kg}$ level, for example, would be expressed as $15 \mathrm{nU}$ ( 15 nanouno) of that phase. Among other advantages, the proposed unit eliminates the present widespread and sometimes ambiguous use of abbreviations such as p.p.m. (for the number $10^{-6}$ ), p.p.b. (for the number $10^{-9}$ in the US and UK, $10^{-12}$ in continental Europe). CCU had proposed the name uno in 1999 but no action was taken at that time by the Comité International des Poids et Mesures. All Directors of National Institutes of Metrology and other relevant institutions are now being canvassed for the widest views on the proposal. Good progress has been made with the proposed IUPAC-NIST Chemical Identifier (see http:// www.iupac.org/projects/2000/2000-025-1-800.html, also the forthcoming report of the Commission on Crystallographic Nomenclature Working Group on Crystal Phase Identifiers). Dissatisfaction with the continued definition of a base unit of the International System of Units (the SI) in terms of a material artefact (the mass of the international prototype of the kilogram, a 90\% Pt, 10\% Ir cylinder kept in a vault in Sèvres, France) has led to the proposal of new definitions for the kilogram [I. M. Mills, P. J. Mohr, T. J. Quinn, B. N. Taylor \& E. R. Williams (2005). Metrologia, 42, 71-80] for consideration by the international nomenclature community.

\section{S. C. Abrahams, IUCr Representative}

\subsection{International Council for Scientific and Technical Information (ICSTI)}

The ICSTI General Assembly was held in London, UK, 13-17 May 2004, at the invitation of INSPEC. A total of 20 members were represented at the meeting by some 35 representatives. The meeting included a one-day public conference entitled Technical and Economic Challenges of Scientific Information (STM Content Access, Linking and Archiving). The conference was well attended and very relevant to the publishing operations of the IUCr. The IUCr was also represented/will be represented by H. D. Flack at the following ICSTI meetings:

Winter committee meeting and discussion meeting on Economic Models for Scientific Information, Production and Distribution, Paris, France, 15-18 January 2004.

Winter committee meeting, Paris, France, 7-9 January 2005.

During 2004, the IUCr undertook a survey in conjunction with ICSTI to determine the extent to which policies and practices are in place to ensure the long-term availability of digital publications and data in the field of crystallography. Individual scientists and organizations were surveyed. The survey focused on formal refereed journal articles, informal publications, theses, published and unpublished data, and personal archives. A report of the findings and recommendations for action will be published during 2005.

ICSTI maintains a public web site at http://www.icsti.org/, where the newsletter ICSTI Forum and other general information is made available. A private section is available only to members, the IUCr Representative sharing this opportunity with the IUCr's SubCommittee on Electronic Publishing, Dissemination and Storage of Information (CEP). A distribution list operates where the ICSTI Executive Director distributes news clips and other information. 
international union of crystallography

In 2005, the ICSTI annual meeting will take place in Moscow, Russia, 25-29 May, organized and sponsored by VINITI. The meeting includes a one-day public conference entitled Information Services for Fundamental and Applied Sciences.

ICSTI is composed of a large spectrum of professionals from the STM and library sectors but with few scientists present. IUCr membership of ICSTI continues to fulfil its expectations by providing a source of current documentation and personal contacts in the field of scientific and technical information (electronic publishing).

\section{P. R. Strickland, IUCr Representative}

\subsection{International Council for Science (ICSU)}

From 9 to 10 February 2004, the Board and Office of ICSU and the ICSU Scientific Union Members met in the Académie des Sciences, Paris, France. ICSU is developing a new strategy that will replace the present scattered way of working. Many new international organizations wish to be members of ICSU, but at present ICSU is lacking a policy to accept new members and has to develop one. Emerging issues will be nanotechnology, proteomic, health and hazards, and Unions were asked to contribute with their expertise. Also, communication should be optimized with a major role for the web site (http://www.icsu.org). ICSU will continue to have a close collaboration with UNESCO for mutual benefit. In particular, the lack of students for sciences was mentioned as a problem of increasing importance.

ICSU is an organization with a small budget and as a result is primarily dependent on volunteers to set up actions and carry them out. In the new grant system, the highest ranking was achieved by the African Institute of Mathematical Sciences as it was supported by five Unions and five National Members. The scientific values of all proposals were about equal, so that priority is given to involvement of many partners. The former small-grants programme made it possible for Unions to use ICSU's name to generate additional sponsorship; however, this scheme has been cancelled. An ongoing effort of ICSU is the free circulation of scientists, which seems to get worse as a result of the security rules, in particular in the USA. One of the main decisions of the General Assembly in 2002 has been the establishment of a new regional structure. As a result, the first ICSU Regional Meeting for Africa was hosted by the Research Council of Zimbabwe in Harare, 9-11 October 2004. D. C. Levendis represented the IUCr at this meeting, at which the decision was taken to open a Regional Office for Africa in Pretoria, South Africa, the host being the National Research Foundation. The ICSU Regional Office will be responsible for the promotion of increased participation of scientists from Sub-Saharan Africa in ICSU programmes and activities. Other regions will follow.

\section{H. Schenk, IUCr Representative}

\subsection{ICSU Programme on Capacity Building in Science (PCBS)}

A Priority Area Assessment (PAA) on Capacity Building is in progress as part of ICSU's overall strategy development process. The PAA will help define ICSU's role and future strategy in the broad area of capacity building, with a particular focus on the needs of developing countries. The immediate outcome of the PAA will be a report and key recommendations that will be published and widely disseminated. This report will form the basis for future actions by ICSU and ICSU family members and partners, including the potential development of new programmes, the development of policy initiatives and definition of priorities for the ICSU grants programme.
The ICSU Programme on Capacity Building in Science (PCBS) has been discontinued.

P. Spadon, IUCr Representative

\subsection{ICSU Committee on Data for Science and Technology (CODATA)}

The major event for CODATA during 2004 was the biennial conference and General Assembly held in Berlin, Germany, 7-12 November, which included a session on the World Summit on the Information Society, and which was attended by the IUCr representative.

\section{CODATA Conference}

CODATA 2004 was billed as the first major interdisciplinary conference addressing new horizons for science in the information society, and the organizers believed that it achieved that goal. There were 260 participants from 28 countries, and activities of most of the Scientific Unions were represented. Participation of representatives from ICSU, UNESCO, IIASA and the African Academy of Languages was taken as evidence of the growth of interest in CODATA.

Presentations of interest to the IUCr were delivered in the Keynote Lectures on open access to knowledge in the sciences and humanities, chemical informatics, biodiversity taxonomy projects and the human genome sequence; and in the meeting sessions on: Data and Society; Mark-up Languages; Data Archiving; Open Scientific Communications/Publication and Citation of Scientific Data; and Data Quality. A full meeting report is available at http://www. iucr.org/iucr-top/data/docs/.

General Assembly

The first session of the 24th General Assembly was an Open Session, in which members of other bodies within the ICSU family were invited to give descriptions of their work. Presentations were made by ICSTI (International Council for Scientific and Technical Information) and INASP (International Network for the Availability of Scientific Publications), and from groups responsible for the CODATA/ICSTI portal on archiving information and the Electronic Geophysical Year.

The Deputy Executive Director of ICSU and the Chair of the ICSU Priority Area Assessment (PAA) Panel on Scientific Data and Information presented the PAA report, a comprehensive review of major issues in the management of scientific data and scientific literature. The report identified shortcomings in the way that the scientific community currently manages data and information, and proposed measures to ensure the healthy future management of data and information. It recommended that ICSU assume a leadership role in tackling critical policy and management issues, in collaboration with its daughter and affiliate organizations, among them CODATA.

CODATA commissioned a response to the report from an internal Committee (K. Lal, Executive Board, CODATA; R. Norris, Representative, IAU; B. McMahon, Representative, IUCr). The Committee made several recommendations, including the publication of a mission statement, development of a strategic plan of action and a number of areas of interest and concern upon which the strategic plan should be based. These recommendations were endorsed by the General Assembly and procedures initiated to address the recommendations and establish a clear long-term strategy for CODATA activities. 
The 2004 CODATA Prize was awarded to J. Bonnin, Professor of Solid Earth Geophysics at Institut de Physique du Globe, Louis Pasteur University, Strasbourg, France.

The Canadian National Committee had established the Sangster Award for graduate students as a specific response to the discussions in the 23rd General Assembly regarding recognition of young scientists' work. A motion was passed encouraging the National, Regional and Associate Members of CODATA to consider establishing similar awards within their own domains.

The General Assembly also passed motions supporting training exchange programmes, thanking the Founding Editor of Data Science Journal, endorsing the Electronic Geophysical Year, and approving the CODATA/ICSTI archiving portal. There was also a motion to send letters of support to National Members of CODATA who were experiencing difficulties in raising the necessary CODATA membership dues.

Beyond the administrative affairs of CODATA, the main function of the General Assembly is the appointment or re-confirmation of Task Groups or Working Groups charged with furthering the objectives of CODATA. The Task Groups approved by the 24th General Assembly for the period 2004-2006 are as follows (those marked with an asterisk are continuations of existing Task Groups): Fundamental Constants*; Preservation and Archiving of Scientific and Technical Data*; Natural Gas Hydrates*; Biological Collection Data Access*; Global Species Data Networks*; Low-Dimensional Materials and Technologies Data Network; Data Sources in AsianOceanic Countries*; Anthropometric Data and Engineering; Virtual Laboratories in Earth, Physics and Environmental Sciences; Data, Information and Visualization*.

Georgia was welcomed as a new National Member of CODATA, and the Republic of Ireland also wished to become a Member.

The Officers of CODATA to the next General Assembly (2006) are: President S. Iwata (Japan); Vice-Presidents A. Gvishiani (Russia) and K. Lal (India); Secretary General R. Chen (USA); Treasurer J.-J. Royer (France). Other members of the Executive Board are listed on the CODATA web site at http://www.codata.org.

\section{World Summit on the Information Society}

CODATA was actively involved in the first phase of the World Summit on the Information Society held in Geneva, Switzerland, in December 2003. The majority of recommendations from the agenda for action (Science in the Information Society) developed with UNESCO were incorporated in the formal Summit Plan of Action. CODATA considers this a success in bringing the concerns of science to the attention of the 172 governments involved in this summit.

Preparations have begun for the second phase of the summit, to be held in Tunis, Tunisia, in November 2005. There was an opportunity for involvement by CODATA members and other interested scientists through a one-day Workshop held during the CODATA 2004 conference. At this Workshop, there were reports of the initiatives within the scientific community arising from the agenda for action, and a round-table discussion of remaining problems and areas of concern. A report of this Workshop is included at the same URL as above, http://www.iucr.org/iucr-top/data/docs/.

\section{Other activities}

The CODATA/ICSTI Prototype Portal on Permanent Access to Scientific Data and Information was launched at the General Assembly. It promises to be an invaluable resource in bringing together relevant initiatives in the archiving of scientific publications and data sets.

CODATA and the auditing/consultancy firm KPMG were successful in a bid to review the Global Biodiversity Information
Facility (GBIF); the review will be carried out by a six-member panel between May 2004 and mid-2005.

CODATA sponsored over a dozen meetings during 2003/4, including the CODATA/ERPANET Workshop on the Selection, Appraisal and Retention of Digital Scientific Data (Portugal, December 2003), the Inter-American Workshop on Access to Environmental Data (Brazil, April 2004) and the Workshop on Strategies for Preservation and Open Access to Digital Scientific Data in China (China, June 2004).

\section{B. McMahon, IUCr Representative}

\subsection{ICSU Committee on Space Research (COSPAR)}

The 35th edition of the COSPAR Scientific Assembly took place 18 July 2004. The scientific Commission on Materials Science in Space was chaired by R. Narayanan, A. Cröll and H. Kawamura. Only one session was devoted to materials science while life origins, extraterrestrial life and obviously space exploration are much more represented.

The 68th COSPAR Bureau Meeting was held in Paris, 21-24 March 2005. The main issue was a comprehensive list of recommendations of all the task groups involved in the reflection on the future of COSPAR, including interface with other organizations (particularly ICSU). The next Bureau meeting will tentatively be held in the week of 20 March 2006.

The next, 36th, edition of COSPAR will be held in Beijing while Canada has issued an invitation to organize COSPAR 2008. Italy has also issued an informal invitation to COSPAR for the same year or 2010.

\section{J. M. Garcia-Ruiz and R. Delhez, IUCr Representatives}

\section{Finances}

The audited accounts of the year 2004 are given at the end of this Report. For comparison, the figures for 2003 are provided in italics. The accounts are presented in CHF.

The UNESCO rates of exchange, as issued by the ICSU Secretariat, have been used in the preparation of these accounts. As a consequence of the many fluctuations in exchange rates during the year, the following procedure has been adopted for the accounts. Assets and liabilities in currencies other than CHF at 31 December 2004 have been translated into CHF in the balance sheet at the rate operative at that date. For the income and expenditure accounts, transactions have been translated into CHF by applying the rates appropriate to the individual dates of these transactions. As a consequence of the fluctuation in exchange rates, an apparent loss has arisen on the assets of the Union, in terms of CHF, amounting to CHF 298,654. The loss attributable to investment activities has been assigned to the General Fund and the loss attributable to trading activities has been divided amongst the fund accounts in direct proportion to the balances on these accounts at 31 December 2004. It should be noted that this loss in CHF is not a real loss of money, but rather a loss on paper resulting from the accounts being expressed in CHF.

Investments are noted in the balance sheet at their market value at 31 December 2004.

The balance sheet shows that the assets of the Union, including the loss of CHF 298,654 resulting from fluctuations in rates of exchange, have decreased during the year, from CHF 4,402,667 to 
CHF 4,251,824. The movement in market value of the investments was CHF 31,190 in 2004 (CHF 272,966 in 2003).

A transfer of CHF 45,000 was made to the Newsletter Fund from the Acta Crystallographica Fund. A transfer of CHF 30,000 was made to the Book Fund from the Journal of Applied Crystallography Fund.

Beneath the detailed figures of the expenditure and income for each fund account, the balance at 1 January, transfers to and from other funds, the difference between income and expenditure for the year and the fluctuations in rates of exchange during the year are given, showing how the balance at 31 December is obtained. Note that for the General Fund there is an additional entry for 'Movement in market value of investments in the year'.

The General Fund account shows a deficit of CHF 156,938, as compared with a deficit in 2003 of CHF 105,661. The administrative expenses were CHF 476,276 in 2004 as compared with CHF 449,259 in 2003. Of this amount, CHF 209,689 was charged to the publications of the Union.

The expenses of the Union Representatives on other bodies were CHF 6,437. The cost of the Finance Committee meetings held in 2004 was CHF 10,917, while the Executive Committee meeting cost CHF 28,990. The income from the IUCr/Fachinformationszentrum agreement (to provide low-cost copies of the Inorganic Crystal Structure Database) was CHF 14,492. The subscriptions from Adhering Bodies were CHF 142,246. Interest on bank accounts and investments credited to the General Fund was CHF 106,058.

The President's Fund, the Publication and Journals Development Fund, the Research and Education Fund and the Ewald Fund received interest, at a nominal rate of $2.5 \%$ per annum, on the balances in the funds.

The President's Fund therefore received interest of CHF 2,217. Grants totalling CHF 6,196 were paid from the fund in 2004.

The Acta Crystallographica account for 2004 shows a surplus of CHF 535,564 before the transfer of CHF 45,000 to the Newsletter Fund, as compared with a surplus of CHF 199,677 in 2003 before transfers of CHF 465,000. The smaller surplus in 2003 is accounted for by the bankruptcy of one of the main subscription agents; this affected all journal publishers.

The subscription rates were increased for 2004. In 2004, the number of paid subscriptions to Sections $A+B+C+D$ of Acta, including 26 (27) personal subscriptions, was 429 (460) (values for 2003 are given in parentheses). The number of paid subscriptions to Sections $A+B+C$, including 8 (13) personal subscriptions, was 105 (130). The number of paid subscriptions to the separate sections of the journal were: Section A 197 (201 for 2003), Section B 152 (154), Section C 118 (122) and Section D 263 (269). The cost of the technical editing office has been divided between the Acta Crystallographica, the Journal of Applied Crystallography, the Journal of Synchrotron Radiation, the International Tables and the Book Fund accounts in percentages based on the staff time spent on each publication. The technical editing costs (comprising salaries and expenses, computer expenses and depreciation of office equipment) for Acta Crystallographica were CHF 1,156,794 (for 10,175 published pages) as compared with $\mathrm{CHF} 1,113,729$ in 2003 (8,735 pages published). The journal's accounts have also been charged with administration expenses as in previous years as shown in the General Fund.

The Journal of Applied Crystallography account shows a surplus of CHF 116,935, as compared with a surplus of CHF 98,138 in 2003. In 2004, the number of paid subscriptions, including 98 (92 in 2003) personal subscriptions, was 632 (652 in 2003).

The Journal of Synchrotron Radiation account shows a deficit of CHF 39,983, as compared with a deficit of CHF 40,179 in 2003 before receiving a transfer of $\mathrm{CHF} 30,000$ from the Acta Crystallographica Fund. In 2004, the number of paid subscriptions, including 65 (70 in 2003) personal subscriptions, was 226 (231 in 2003).

The International Tables account shows a surplus of CHF 53,244, as compared with a surplus of CHF 80,060 in 2003. The net sales income was CHF 253,992 in 2004 as compared with CHF 221,331 in 2003.

The Book Fund is credited with the sales of the remaining publications of the Union. The deficit of CHF 108,998 is attributable to the programming time involved in the restructuring and updating of the World Database of Crystallographers, which is used to produce the World Directory of Crystallographers.

The Newsletter Fund account received a transfer of CHF 45,000 from the Acta Crystallographica Fund in 2004 (CHF 45,000 from the Journal of Applied Crystallography Fund in 2003). The cost to the Union of producing the Newsletter in 2004 was CHF 50,592 (CHF 29,165 in 2003). The difference is accounted for by the fact that advertising revenue for five issues was received in 2003, compared with income for four issues in 2004.

As mentioned earlier, the income for the President's Fund account, the Publications and Journals Development Fund account, the Research and Education Fund account and the Ewald Fund account includes interest as well as transfers from other fund accounts. In the Publications and Journals Development Fund account, the computing and promotion expenses are divided between the General Fund, the Acta Crystallographica Fund, the Journal of Applied Crystallography Fund, the Journal of Synchrotron Radiation Fund, the International Tables Fund and the Book Fund. STAR/CIF costs, Special Issue costs, journal grants and web input costs are also charged to the Publication and Journals Development account. From 2000, costs associated with the Crystallographic NeXus Project to provide CD-ROMs (containing crystallographic software and web material) free of charge to developing countries has been charged to this Fund. In 2004, CHF 46,301 was provided from this Fund as journal subsidies in connection with the Journal Grants Fund, which was set up to assist institutions that have difficulties in meeting the full subscription price. CHF 119,382 for financial support to young scientists, to enable them to attend scientific meetings sponsored by the Union was charged to the Research and Education Fund.

\section{Auditor's Report to the International Union of Crystallography}

We have audited the financial statements of the International Union of Crystallography for the year ended 31 December 2004, which comprise the income and expenditure account, the balance sheet, the cash flow statement and the related notes 15.1 to 15.15 . These financial statements have been prepared under the accounting policies set out therein.

This report is made solely to the Union's members, as a body, in accordance with Section 11.1 of the Statutes of the Union. Our audit work has been undertaken so that we might state to the Union's members those matters we are required to state to them in an auditor's report and for no other purpose. To the fullest extent permitted by law, we do not accept or assume responsibility to anyone other than the Union and the Union's members as a body, for our audit work, for this report, or for the opinions we have formed.

Respective responsibilities of Executive Committee and Auditors

As described in the statement of the Executive Committee's responsibilities (see §16), the Executive Committee is responsible for 
the preparation of the financial statements in accordance with applicable law and accounting standards.

Our responsibility is to audit the financial statements in accordance with relevant legal and regulatory requirements and United Kingdom auditing standards.

We report to you our opinion as to whether the financial statements give a true and fair view. We also report if, in our opinion, the Union has not kept proper accounting records and if we have not received all information and explanations we require for our audit. Basis of audit opinion

We conducted our audit in accordance with United Kingdom auditing standards issued by the Auditing Practices Board. An audit includes examination, on a test basis, of evidence relevant to the amounts and disclosures in the financial statements. It also includes an assessment of the significant estimates and judgments made in the preparation of the financial statements, and of whether the accounting policies are appropriate to the Union's circumstances, consistently applied and adequately disclosed.

We planned and performed our audit so as to obtain all the information and explanations which we considered necessary in order to provide us with sufficient evidence to give reasonable assurance that the financial statements are free from material misstatement, whether caused by fraud or other irregularity or error. In forming our opinion, we also evaluated the overall adequacy of the presentation of information in the financial statements.

\section{Opinion}

In our opinion, the financial statements give a true and fair view of the state of the Union's affairs as at 31 December 2004 and of the result for the year then ended.

Deloitte \& Touche LLP

Chartered Accountants and Registered Auditors

Manchester

13 June 2005

\section{Notes to the Accounts}

The Income and Expenditure Account, the Balance sheet and the Cash Flow statement for the year ended 31 December 2004 are given in Tables 2, 3 and 4.

\subsection{Accounting policies}

\section{(a) Accounting convention}

The financial statements are prepared under the historical cost convention, with the exception of investments which are stated at market value, and in accordance with applicable United Kingdom accounting standards. The particular accounting policies adopted are described below.

\section{(b) Rates of exchange}

UNESCO rates of exchange as issued by the ICSU Secretariat are used in the preparation of the financial statements.

Transactions denominated in foreign currencies are translated into Swiss Francs at the rates ruling at the dates of the transactions. Monetary assets and liabilities denominated in foreign currencies at the balance sheet date are retranslated at the rates ruling at that date.

Profits and losses arising on trading transactions from the fluctuations in rates of exchange during the year are divided between the fund accounts with credit balances in direct proportion to those balances at the closing balance sheet date. Profits and losses on investments are allocated to the General Fund. All profits and losses arising from exchange rate fluctuations are taken directly to reserves.

(c) Publication costs

Publication, editorial and administrative expenses of publications are charged in the appropriate income and expenditure account as and when incurred.

(d) Stocks

Stocks of International Tables are included at the lower of cost and net realizable value. Stocks of all other publications, including back issues of journals, are not valued for accounts purposes as sales are uncertain.

(e) Expenditure on premises

Expenditure on maintenance of leasehold premises is charged against the appropriate income and expenditure accounts in the year in which it is incurred.

( $f$ ) Depreciation

(i) Office equipment is depreciated on the straight line basis at a rate of $20 \%$ per annum.

(ii) Office computer equipment is depreciated on a straight basis at a rate of $33 \frac{1}{3} \%$ per annum.

(iii) Leasehold property improvements are depreciated over the term of the lease.

(g) Investment income

Notional dividend income re-invested in accumulation investment funds is treated as income when declared and added to the accumulated cost of investments. Other dividends are recognized on an accruals basis.

(h) Investments

Investments are stated at market value. Changes in market value are taken directly to reserve movements in the General Fund.

(i) Lease costs

Operating lease costs are charged to the income and expenditure account on a straight line basis over the term of the lease. Where reduced rents are payable on property in the earlier years of the lease, the total cost for the period to the first rent review date is spread on a straight line basis, and the appropriate creditor balance is maintained.

(j) Pension costs

The Union operates a defined contribution pension scheme for its employees. The assets of the scheme are held separately from those of the Union. The amount charged to income and expenditure in the year in respect of pensions represents employer's contributions payable in the year. No amounts were due to or from the pension scheme at 31 December 2004 (the same was true in 2003).

\subsection{Rates of exchange}

The assets of the Union are recorded in the financial statements in Swiss Francs but are held in currencies which are considered to be appropriate to the Union's requirements. Transactions in currencies other than Swiss Francs are converted into Swiss Francs at the rate of exchange ruling on the date of the transaction.

The rates of exchange operative at the balance sheet date compared with the Swiss Franc were as follows:

$\begin{array}{lll} & 2004 & 2003 \\ \text { Euros (EUR) } & 0.6614 & 0.6477 \\ \text { Danish Crowns (DKK) } & 4.9211 & 4.8231 \\ \text { Pounds Sterling (GBP) } & 0.4649 & 0.4462 \\ \text { US Dollars (USD) } & 0.8772 & 0.7692\end{array}$


international union of crystallography

Table 2

Income and Expenditure Account for the year ended 31 December 2004.

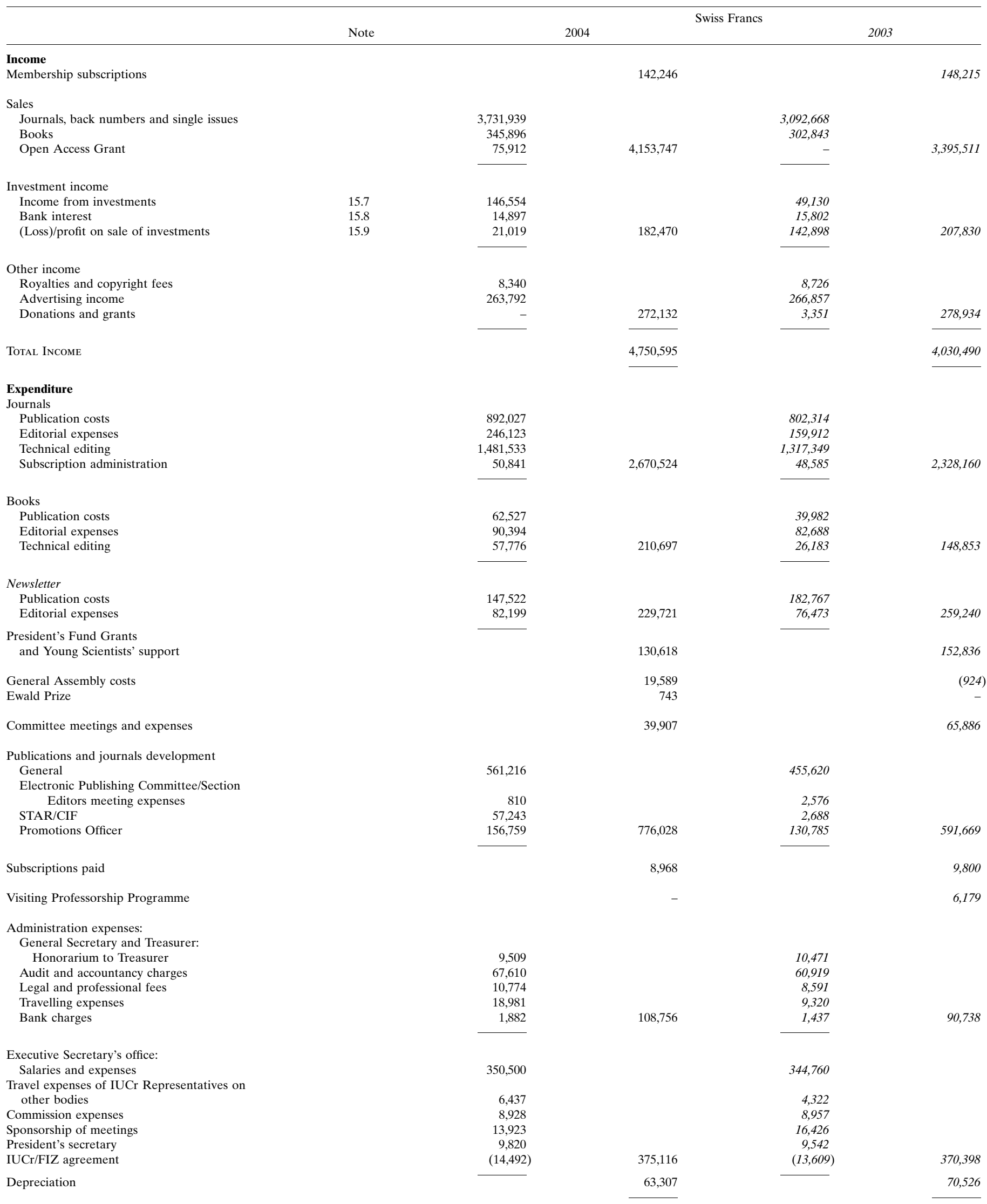




\section{international union of crystallography}

Table 2 (continued)

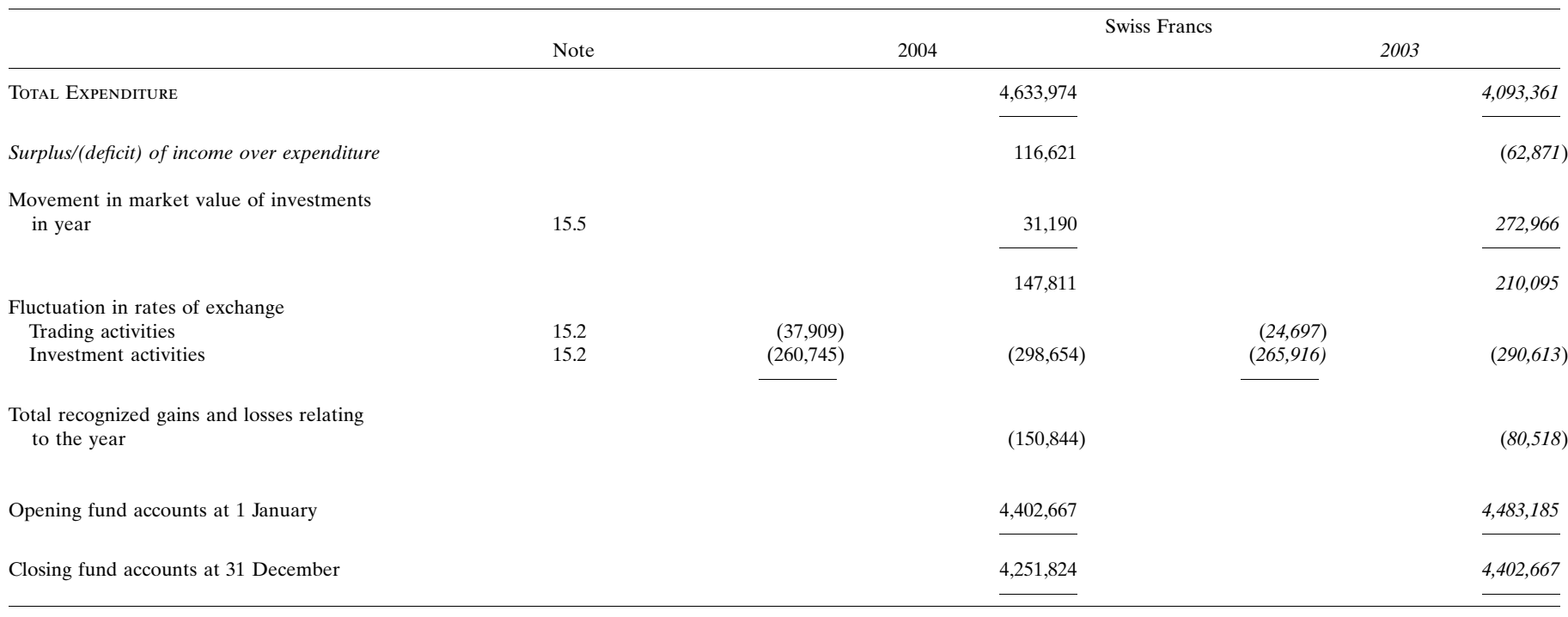

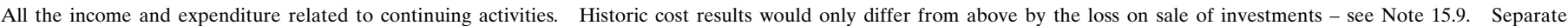
Statements of Total Recognized Gains and Losses and Reconciliation of Movements in Fund Account are not given, as the information is incorporated in the above.

Table 3

Balance sheet as at 31 December 2004.

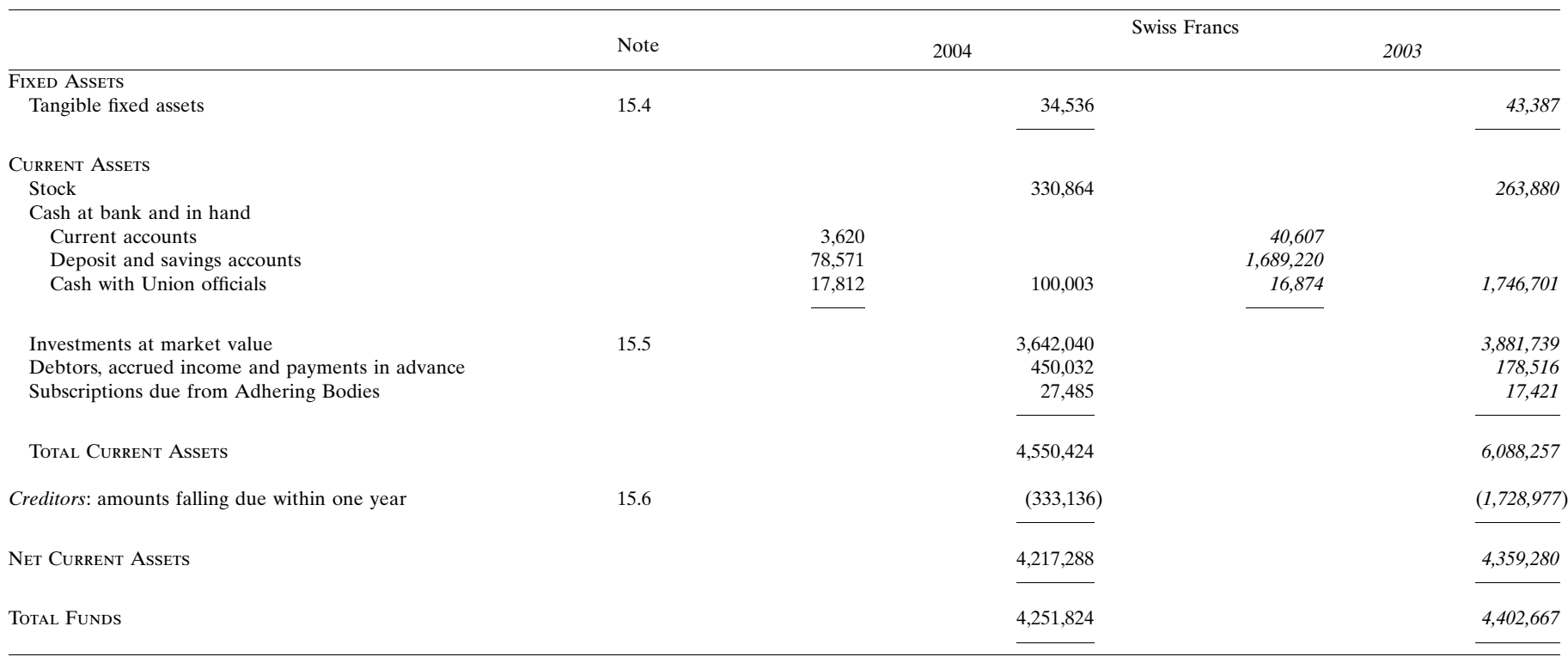

The net assets of the Union at 1 January 2004 (CHF 4,402,667) would have had the value of USD $3,386,531$ or GBP $1,964,470$ if expressed in those currencies.

At 31 December 2004, the net assets (CHF 4,251,824) would have had the value of USD 3,729,700 or GBP 1,976,673, respectively, being an increase of USD 343,169 or an increase of GBP 12,203 from the previous year.

\subsection{Taxation}

As an association incorporated in Switzerland, the Union is exempt from Swiss Federal and Geneva Cantonal tax. Under the terms of the United Kingdom/Switzerland Double Taxation Agreement dated 8 December 1977, investment income arising within the United
Kingdom under present circumstances will not be subject to United Kingdom tax.

Other investment income received from countries with which Switzerland has a Double Taxation Agreement is exempt from tax.

\subsection{Tangible fixed assets}

Table 5 lists the tangible fixed assets.

\subsection{Investments}

Table 6 lists the investments of the IUCr, their disposals and additions and the holding at 31 December 2004. 
Table 4

Cash Flow statement for the year ended 31 December 2004.

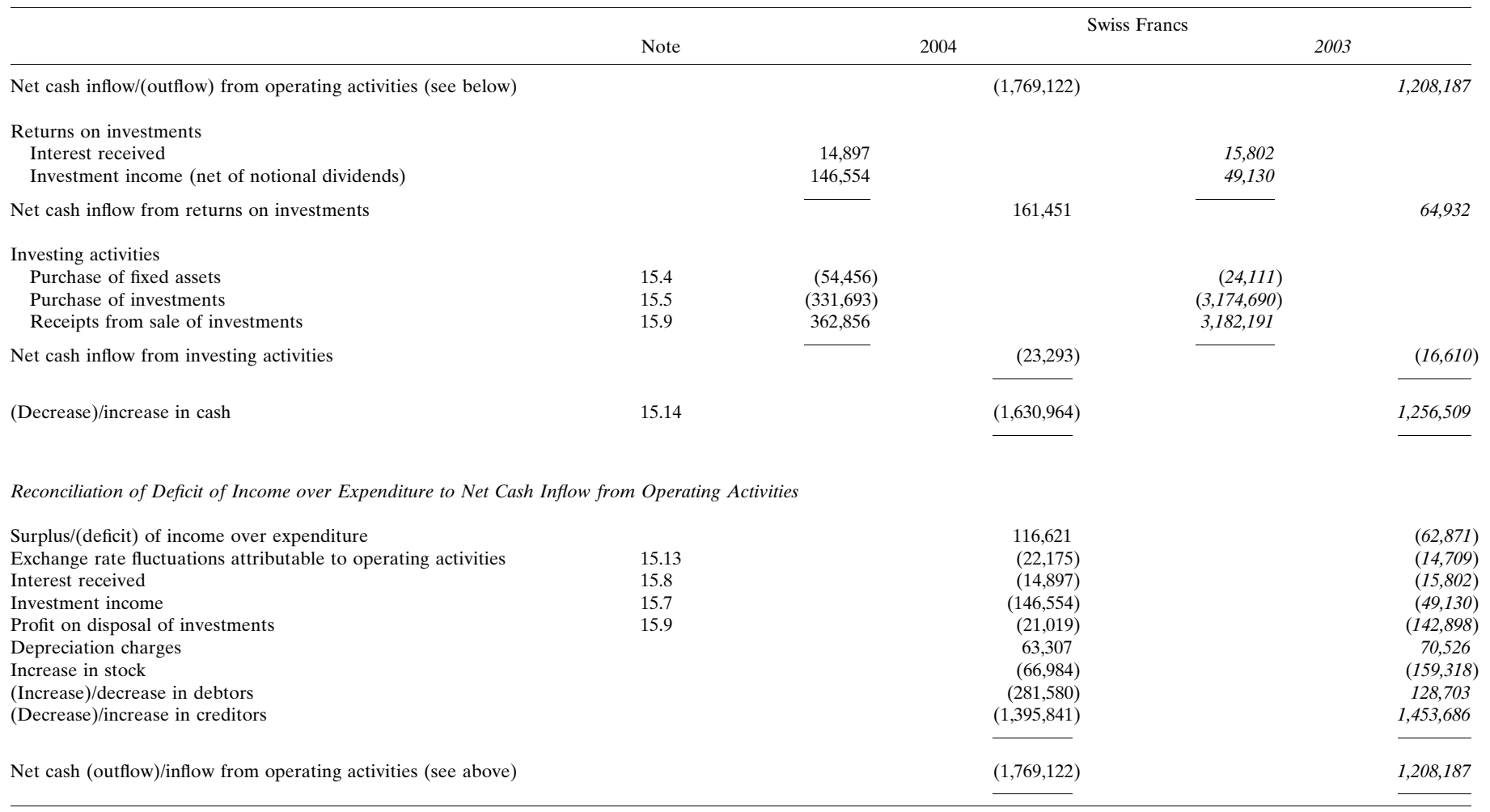

Table 5

Tangible fixed assets.

\begin{tabular}{|c|c|c|c|c|}
\hline & $\begin{array}{l}\text { Leasehold property } \\
\text { improvements } \\
\text { CHF }\end{array}$ & $\begin{array}{c}\text { Office } \\
\text { equipment } \\
\text { CHF }\end{array}$ & $\begin{array}{l}\text { Computer } \\
\text { equipment } \\
\text { CHF }\end{array}$ & $\begin{array}{l}\text { Total } \\
\text { CHF }\end{array}$ \\
\hline \multicolumn{5}{|l|}{ Cost } \\
\hline \multicolumn{5}{|l|}{ As at } \\
\hline 1 January 2004 & 102,987 & 92,698 & 357,702 & 571,387 \\
\hline Additions & - & - & 54,456 & 54,456 \\
\hline \multicolumn{5}{|l|}{ As at } \\
\hline 31 December 2004 & 102,987 & 92,698 & 430,158 & 625,843 \\
\hline \multicolumn{5}{|l|}{ Accumulated depreciation } \\
\hline \multicolumn{5}{|l|}{ As at } \\
\hline 1 January 2004 & 84,730 & 83,369 & 359,901 & 528,000 \\
\hline Charge for the year & 10,299 & 4,161 & 48,847 & 63,307 \\
\hline \multicolumn{5}{|l|}{ As at } \\
\hline 31 December 2004 & 95,029 & 87,530 & 408,748 & 591,307 \\
\hline \multicolumn{5}{|l|}{ Net book value } \\
\hline 31 December 2004 & 7,958 & 5,168 & 21,410 & 34,536 \\
\hline 31 December 2003 & 18,257 & 9,329 & 15,801 & 43,387 \\
\hline
\end{tabular}

\subsection{Creditors}

Table 7 lists the creditors, with the amounts falling due within one year for 2003 and 2004.

\subsection{Investment income}

Table 8 lists the income from investments for 2003 and 2004.

\subsection{Bank interest}

Table 9 lists the bank interest for 2003 and 2004.

\subsection{Loss/profit on disposal/redemption of investments}

Table 10 lists the loss or profit on disposal/redemption of investments for 2003 and 2004.

\subsection{Information regarding employees}

Staff costs during the years 2003 and 2004 are given in Table 11.

\subsection{Operating lease commitments}

At 31 December 2004, the Union was committed to making the payments listed in Table 12 during the next year in respect of operating leases.

\subsection{Sponsorship and other financial commitments}

At 31 December 2004, the Union had authorized, but not contracted for, sponsorship grants of CHF 26,220 (2003: CHF 42,900).

At 31 December 2004, the Union had authorized, but not contracted for, a new CIF software agreement of CHF 28,036 (2003: CHF 0).

15.13. Exchange rate fluctuations attributable to operating activities

Table 13 lists exchange rate fluctuations attributable to operating activities for 2003 and 2004. 
Table 6

Investments.

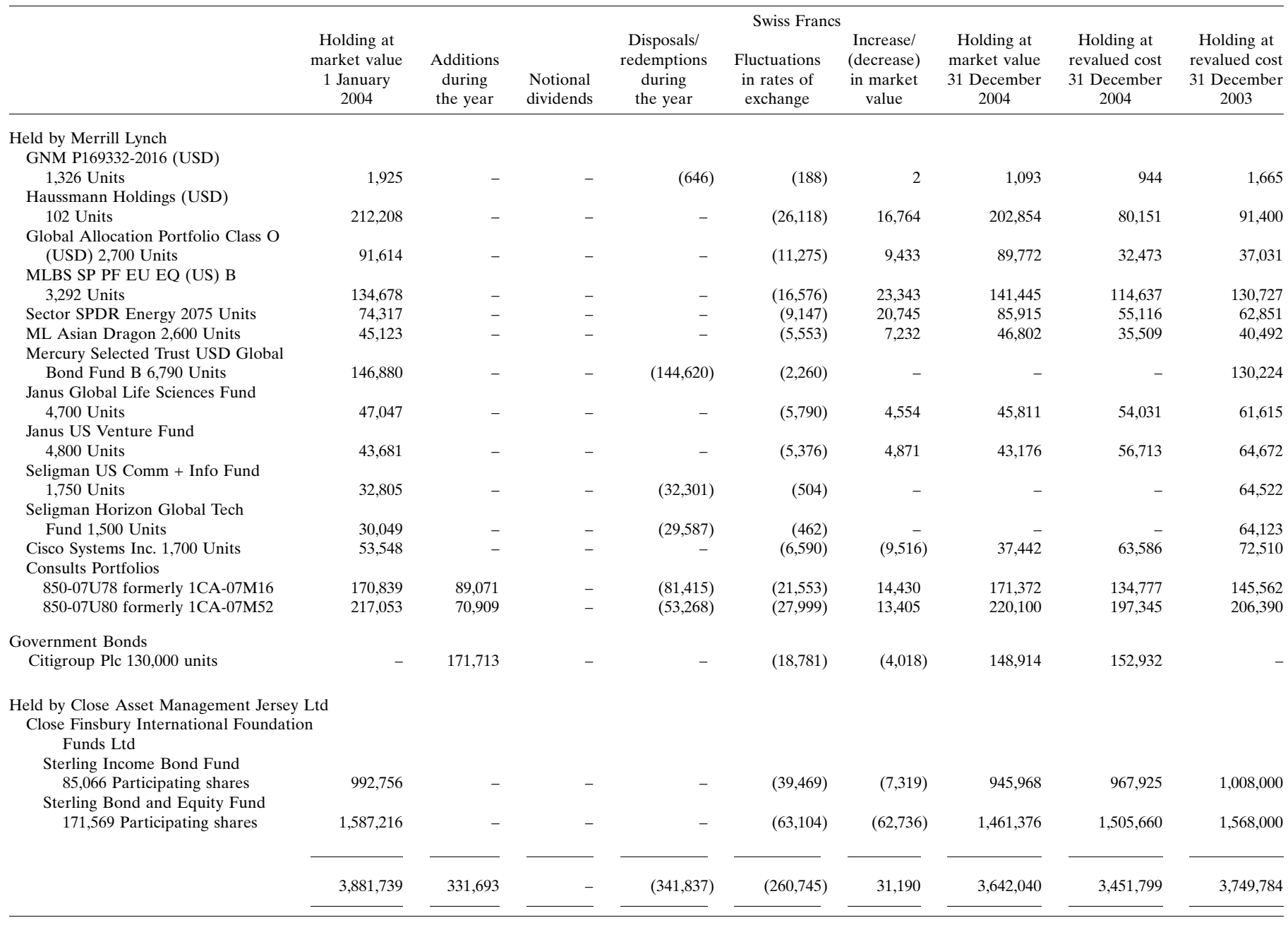

\subsection{Analysis of changes in cash during the year}

Table 14 is an analysis of cash changes during 2003 and 2004.

\subsection{Analysis of balances of cash as shown in the balance sheet}

Table 15 is an analysis of cash balances as shown in the balance sheet.

Tables 16-27 give the accounts for the year ended 31 December 2004 for the various fund accounts.

\section{Statement of the Executive Committee's responsibilities}

The Statutes and By-laws of the Union require the Treasurer to exhibit a general statement of the pecuniary affairs of the Union with detailed accounts of the income and expenditure. In preparing these accounts, the Executive Committee is required to:

(i) select suitable accounting policies and then apply them consistently; (ii) make judgments and estimates that are reasonable and prudent;

(iii) prepare the accounts on the going concern basis unless it is inappropriate to presume the Union will continue.

These accounts are to be audited by a professional auditor appointed by the Executive Committee.

The Executive Committee is responsible for keeping proper accounting records which disclose with reasonable accuracy at any time the financial position of the Union, and to ensure that the accounts comply with the Constitution of the Union. They are also responsible for safeguarding the assets of the Union and hence for taking reasonable steps for the prevention and detection of fraud and other irregularities.

By order of the Executive Committee

Professor S. Larsen, General Secretary and Treasurer Professor W. L. Duax, President

M. H. Dacombe, Executive Secretary 
international union of crystallography

Table 7

Creditors: amounts falling due within one year.

\begin{tabular}{|c|c|c|}
\hline & \multicolumn{2}{|c|}{ Swiss Francs } \\
\hline & 2004 & 2003 \\
\hline \multirow{3}{*}{$\begin{array}{l}\text { Creditors and accruals } \\
\text { Payroll creditor including tax and social security }\end{array}$} & 274,487 & $1,677,010$ \\
\hline & 58,649 & 51,967 \\
\hline & 333,136 & $1,728,977$ \\
\hline
\end{tabular}

Table 8

Investment income.

\begin{tabular}{|c|c|c|}
\hline & \multicolumn{2}{|c|}{ Swiss Francs } \\
\hline & 2004 & 2003 \\
\hline GNM P169332 - 2016 & 96 & 244 \\
\hline Haussmann Holdings & 261 & 288 \\
\hline UK Treasury $7.75 \% 22.9 .2006$ & - & 25,758 \\
\hline Sector SPDR Strategy & 925 & 1,248 \\
\hline Pharmaceutical & - & 11 \\
\hline Close Finsbury International Ltd Sterling Income Bond Fund & 58,360 & 14,300 \\
\hline Close Finsbury International Ltd Sterling Bond and Equity Fund & 78,349 & \\
\hline \multicolumn{3}{|l|}{ Consults Portfolios } \\
\hline 850-07U78 & 3,016 & 3,290 \\
\hline \multirow{2}{*}{$850-07 \mathrm{U} 80$} & 5,547 & 3,991 \\
\hline & 146,554 & 49,130 \\
\hline \multicolumn{3}{|l|}{ Allocated to: } \\
\hline President's Fund & 2,127 & 1,717 \\
\hline Publication and Journals Development Fund & 18,671 & 16,055 \\
\hline Research and Education Fund & 22,225 & 21,433 \\
\hline Ewald Fund & 12,280 & 11,452 \\
\hline \multirow[t]{2}{*}{ Balance left in General Fund } & 91,161 & $(1,527$ \\
\hline & 146,554 & 49,130 \\
\hline
\end{tabular}

Table 9

Bank interest.

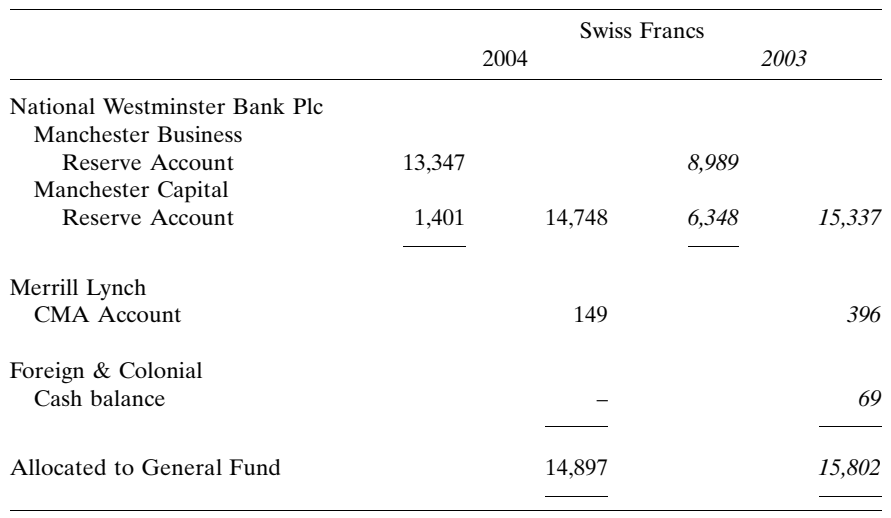

Table 10

Profit on disposal/redemption of investments.

\begin{tabular}{lccc}
\hline & 2004 & Swiss Francs & 2003 \\
\hline Proceeds & 362,856 & $3,182,191$ \\
Book value & $\underline{31,837}$ & $\underline{3,039,293}$ \\
Profit allocated to General Fund & $\mathbf{2 1 , 0 1 9}$ & $\underline{142,898}$ \\
\hline
\end{tabular}

Book value represents market value at 1 January 2004 or cost if acquired after that date. The loss on disposal based on historic cost was CHF 27,271 (2003: profit of CHF 44,149). Therefore historic cost results would be as follows:

\begin{tabular}{lccc}
\hline & 2004 & Swiss Francs & 2003 \\
\hline Deficit of income over expenditure & $(48,084)$ & $(161,620)$ \\
\hline
\end{tabular}

Table 11

Information regarding employees.

\begin{tabular}{|c|c|c|}
\hline & 2004 & 2003 \\
\hline \multirow[t]{2}{*}{$\begin{array}{l}\text { Average number of persons employed } \\
\text { during the year }\end{array}$} & 23 & 23 \\
\hline & \multicolumn{2}{|c|}{ Pounds Sterling } \\
\hline \multicolumn{3}{|l|}{$\begin{array}{l}\text { Staff costs incurred during the year in } \\
\text { respect of these employees: }\end{array}$} \\
\hline Salaries & 753,005 & 722,523 \\
\hline Social security & 83,020 & 77,145 \\
\hline Pension & 131,173 & 122,813 \\
\hline \multirow[t]{3}{*}{ Total staff costs } & 967,200 & 922,481 \\
\hline & \multicolumn{2}{|c|}{ Swiss Francs } \\
\hline & 2004 & 2003 \\
\hline
\end{tabular}

Total staff costs

Table 12

Operating lease commitments.

\begin{tabular}{|c|c|c|c|c|}
\hline & \multicolumn{4}{|c|}{ Swiss Francs } \\
\hline & $\begin{array}{l}\text { Land and } \\
\text { Buildings } \\
2004\end{array}$ & $\begin{array}{l}\text { Other } \\
2004\end{array}$ & $\begin{array}{l}\text { Land and } \\
\text { Buildings } 2003\end{array}$ & $\begin{array}{l}\text { Other } \\
2003\end{array}$ \\
\hline \multirow{5}{*}{$\begin{array}{l}\text { Leases which expire: } \\
\text { within one year } \\
\text { within one to two years } \\
\text { within two to five years } \\
\text { after five years }\end{array}$} & & & & \\
\hline & 55,923 & $2,30 \overline{-}$ & - & 6,185 \\
\hline & 24,735 & 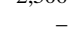 & 58,266 & \\
\hline & - & - & 25,772 & \\
\hline & 80,658 & 2,306 & 84,038 & 6,185 \\
\hline
\end{tabular}




\section{international union of crystallography}

Table 13

Exchange rate fluctuations attributable to operating activities.

\begin{tabular}{lcc}
\hline & 2004 & Swiss Francs \\
& & 2003 \\
\hline $\begin{array}{l}\text { Total fluctuations in exchange rates dealt } \\
\text { with in fund accounts }\end{array}$ & $(298,654)$ & \\
Adjustments for exchange differences & & \\
$\quad$ attributable to: & $290,613)$ \\
$\quad$ Investments (Note 15.5) & 260,745 & \\
$\quad$ Cash and bank balances & 15,734 & 265,916 \\
& & 9,988 \\
\hline
\end{tabular}

Table 14

Analysis of changes in cash during the year.

\begin{tabular}{|c|c|c|c|c|}
\hline \multirow{4}{*}{$\begin{array}{l}\text { Balance at } 1 \text { January } \\
\text { Net cash (outflow)/inflow }\end{array}$} & \multicolumn{4}{|c|}{ Swiss Francs } \\
\hline & \multicolumn{2}{|c|}{2004} & \multicolumn{2}{|c|}{2003} \\
\hline & & $1,746,701$ & & 500,180 \\
\hline & $(1,630,964)$ & & $1,256,509$ & \\
\hline \multirow{2}{*}{$\begin{array}{l}\text { Fluctuations in rates } \\
\text { of exchange on cash } \\
\text { and bank balances }\end{array}$} & & & & \\
\hline & $(15,734)$ & $(1,646,698)$ & $(9,988)$ & $1,246,521$ \\
\hline $\begin{array}{l}\text { Balance at } \\
\quad 31 \text { December } 2004\end{array}$ & & 100,003 & & $1,746,701$ \\
\hline
\end{tabular}

Table 15

Analysis of cash balances as shown in the Balance sheet.

\begin{tabular}{lcccc}
\hline & \multicolumn{3}{c}{ Swiss Francs } \\
& 2004 & 2003 & $\begin{array}{c}\text { Change } \\
2004\end{array}$ & $\begin{array}{c}\text { Change } \\
\text { 2003 }\end{array}$ \\
\hline Cash at bank and in hand & 100,003 & $1,746,701$ & $\underline{(1,646,698)}$ & $1,246,521$ \\
\hline
\end{tabular}

Table 16

Fund Accounts as at 31 December 2004.

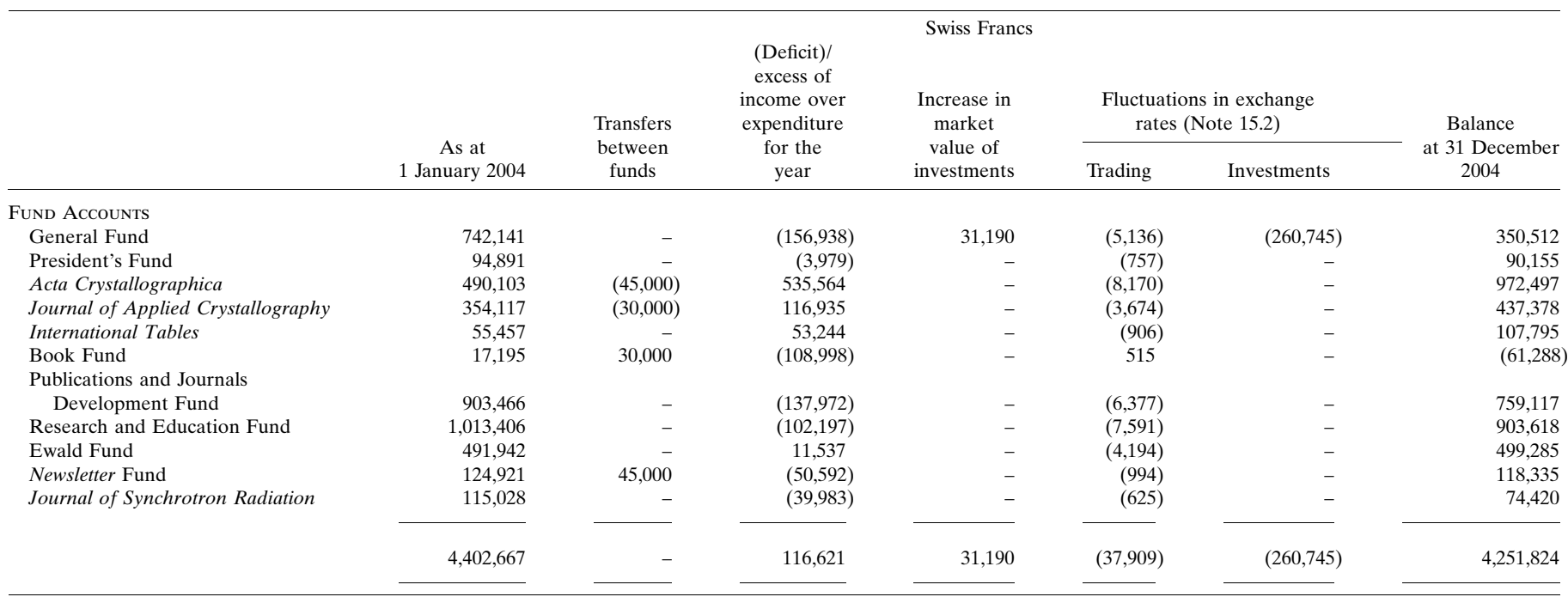


international union of crystallography

Table 17

General Fund Account for the year ended 31 December 2004.

\begin{tabular}{|c|c|c|c|c|c|}
\hline \multirow{3}{*}{$\begin{array}{l}\text { Income } \\
\text { Subscriptions from Adhering Bodies }\end{array}$} & Note & \multicolumn{4}{|c|}{ Swiss Francs } \\
\hline & & & & & \\
\hline & & & 142,246 & & 148,215 \\
\hline Income/(expense) from investments & 15.7 & & 91,161 & & $(1,527)$ \\
\hline Profit on disposal/redemption of investments & 15.9 & & 21,019 & & 142,898 \\
\hline \multicolumn{6}{|l|}{ Amounts charged to the following journals and publications: } \\
\hline Acta Crystallographica & & 181,948 & & 160,712 & \\
\hline Total Income & & & 479,012 & & 502,921 \\
\hline \multicolumn{6}{|l|}{ Expenditure } \\
\hline Subscriptions to ICSU and ICSU bodies & & & 8,968 & & 9,800 \\
\hline \multirow{2}{*}{\multicolumn{6}{|c|}{$\begin{array}{l}\text { Administrative expenses: } \\
\text { General Secretary and Treasurer: }\end{array}$}} \\
\hline \multicolumn{5}{|l|}{ General Secretary and Treasurer: } & \\
\hline \multicolumn{6}{|l|}{ Executive Secretary's office: } \\
\hline Salaries and expenses & & 350,500 & & 344,760 & \\
\hline Depreciation of office equipment & & 6,721 & & 3,463 & \\
\hline Depreciation of leasehold improvements & & 10,299 & 476,276 & 10,299 & 449,259 \\
\hline \multicolumn{6}{|l|}{ Twentieth/Nineteenth General Assembly and Congress } \\
\hline Expenses & & 19,589 & & (924) & \\
\hline Programming and development costs & & 49,194 & & 44,405 & \\
\hline Promotion & & 17,400 & & 14,517 & \\
\hline Meeting of the Executive Committee & & 28,990 & & 54,125 & \\
\hline Finance Committee expenses & & 10,917 & & 11,761 & \\
\hline Travel expenses of IUCr Representatives on other bodies & & 6,437 & & 4,323 & \\
\hline Commission expenses & & 8,928 & & 8,957 & \\
\hline Sponsorship of meetings & & 13,923 & & 16,426 & \\
\hline President's secretary & & 9,820 & & 9,542 & \\
\hline \multicolumn{6}{|l|}{ Reconciliation of movements } \\
\hline Movement in market value of investments in the year & 15.5 & 31,190 & $(125,748)$ & 272,966 & 167,305 \\
\hline Fluctuations in rates of exchange & & & $(265,881)$ & & $(271,249)$ \\
\hline Balance at 31 December & & & 350,512 & & 742,141 \\
\hline
\end{tabular}




\section{international union of crystallography}

Table 18

Acta Crystallographica Account for the year ended 31 December 2004

Note

Swiss Francs

2004

2003

Income

Subscriptions to Volume 60 (2003 Volume 59) and sale of back

numbers and single copies

Distribution costs charged to subscribers

Royalties and copyright fees

Special Issue income

Pay per view and secondary services (net)

$3,052,467$

23,353

13,305

19,924

$3,109,049$

350,478

Less Publisher's commission on sales

Income from advertisements (net)

Recharge for Special Issue

Total Income

Expenditure

Publication expenses:

Production Volume 60 (2003 Volume 59)

Distribution costs

Net profit on reprints

Special Issue costs

Editorial expenses:

Editorial honoraria

Secretarial assistance

Postage, travel and sundries

Technical editing:

Salaries and expenses

Computer expenses

Subscription administration

Promotion

Depreciation of office equipment

Programming and development cost

Administration expenses recharged from General Fund

TOTAL EXPENDITURE

Surplus of income over expenditure

Reconciliation of movements

Balance at 1 January

Transfers to other funds

Book Fund

Publications and Journals Development Fund

Research and Education Fund

Newsletter Fund

Journal of Synchrotron Radiation

President's Fund
336,646

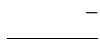

336,646

$(14,308)$

13,305

190,259

10,244

21,662

$1,091,486$

44,760

38,131

70,071

20,548

-
1,487,161

2,758,571

33,126

2,791,697

2,365,195

172,494

16,565

$(11,692)$

2,370,068

344,023

88,220

432,243

$(31,637)$

10,945

411,551

335,643

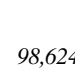

10,765

20,348

1,017,332

87,853

36,438

58,461

8,544

$1,338,365$

251,381

181,948

259,763

160,712

$2,256,133$

2,170,391

535,564

199,677

490,103

758,019

$(20,000)$

$(250,000)$

$(140,000)$

$(45,000)$

$(30,000)$

$(25,000)$

$(465,000)$

$(45,000)$

199,677

535,564

$(8,170)$

972,497 
international union of crystallography

Table 19

Journal of Applied Crystallography Account for the year ended 31 December 2004.

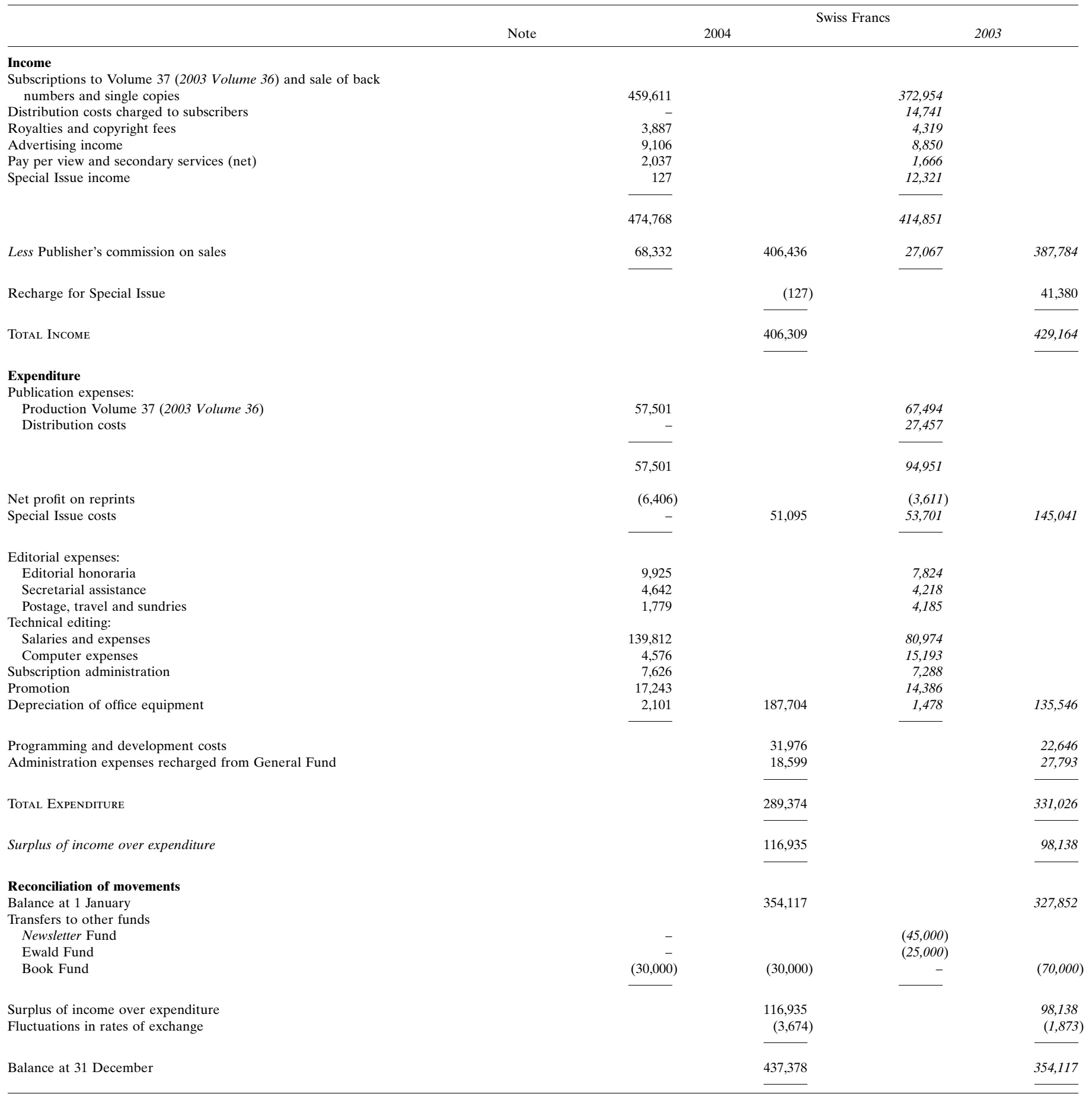




\section{international union of crystallography}

Table 20

Journal of Synchrotron Radiation Account for the year ended 31 December 2004.

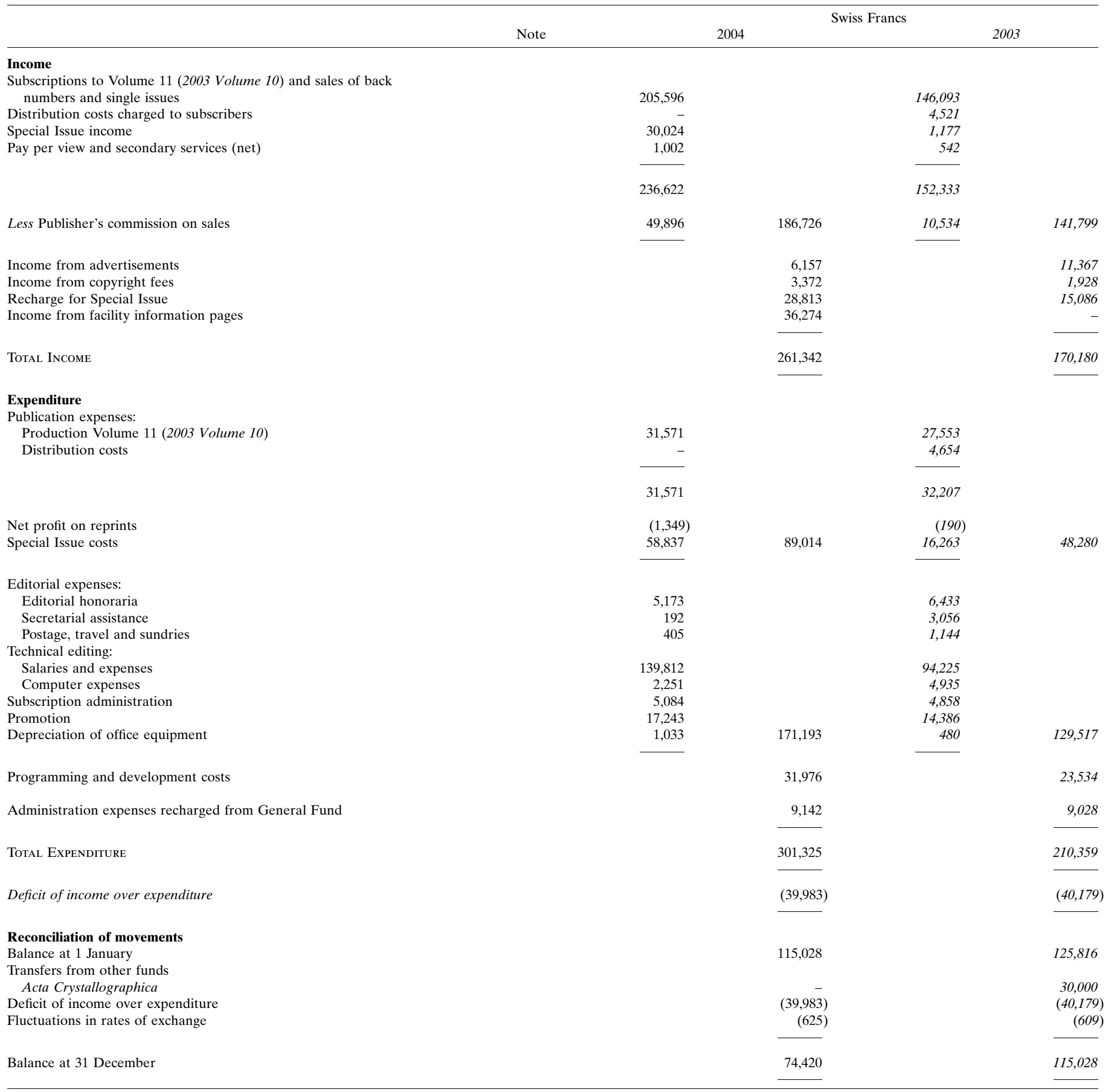


international union of crystallography

Table 21

President's Fund Account for the year ended 31 December 2004.

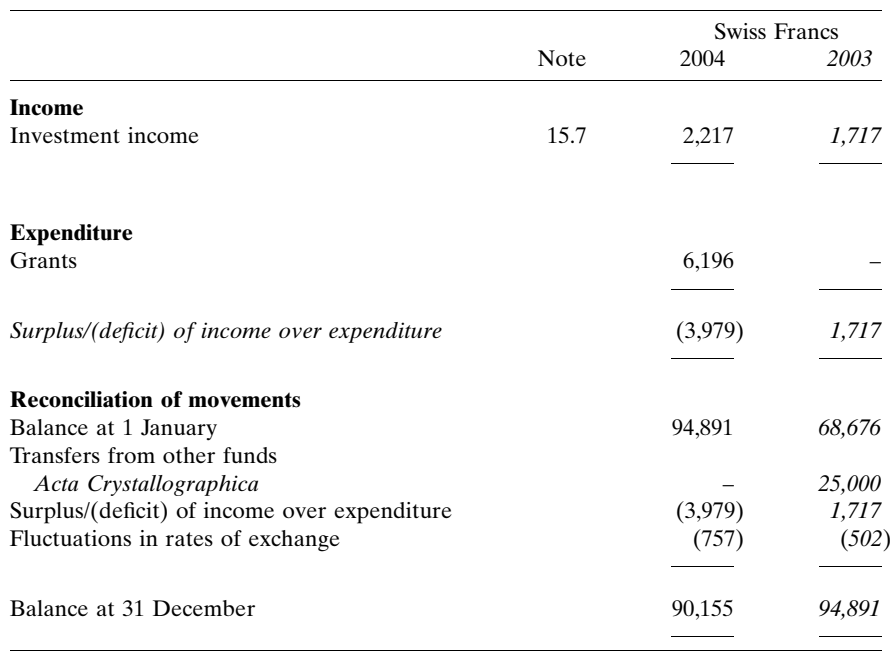

Table 23

Book Fund Account for the year ended 31 December 2004.

\begin{tabular}{|c|c|c|c|}
\hline \multirow{2}{*}{ 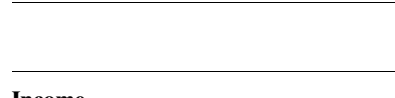 } & \multirow[b]{2}{*}{ Note } & \multicolumn{2}{|c|}{ Swiss Francs } \\
\hline & & 2004 & 2003 \\
\hline \multicolumn{4}{|c|}{ Income } \\
\hline \multicolumn{4}{|c|}{ Sales of copies, net of Publisher's commission on sales } \\
\hline Historical Atlas of Crystallography & & 138 & 2 \\
\hline \multicolumn{4}{|c|}{ World Directory of Crystallographers and } \\
\hline Structure Reports & & 406 & 964 \\
\hline \multicolumn{4}{|l|}{ Royalties } \\
\hline IUCr/OUP Book Series & & 1,081 & 2,479 \\
\hline Sundry publications & & 108 & 176 \\
\hline Total Income & & 4,554 & 7,651 \\
\hline \multicolumn{4}{|l|}{ Expenditure } \\
\hline World Directory of Crystallographers & & 1,368 & 1,584 \\
\hline Programming and development & & 94,784 & 19,538 \\
\hline Promotion & & 17,400 & 14,517 \\
\hline Total Expenditure & & 113,552 & 35,639 \\
\hline Deficit of income over expenditure & & $(108,998)$ & $(27,988)$ \\
\hline \multicolumn{4}{|l|}{ Reconciliation of movements } \\
\hline Balance at 1 January & & 17,195 & 25,274 \\
\hline \multicolumn{4}{|l|}{ Transfers from other funds } \\
\hline Acta Crystallographica & & - & 20,000 \\
\hline Journal of Applied Crystallography & & 30,000 & \\
\hline Deficit of income over expenditure & & $(108,998)$ & $(27,988)$ \\
\hline Fluctuations in rates of exchange & & 515 & (91) \\
\hline Balance at 31 December & & $(61,288)$ & 17,195 \\
\hline
\end{tabular}

Table 22

International Tables Account for the year ended 31 December 2004.

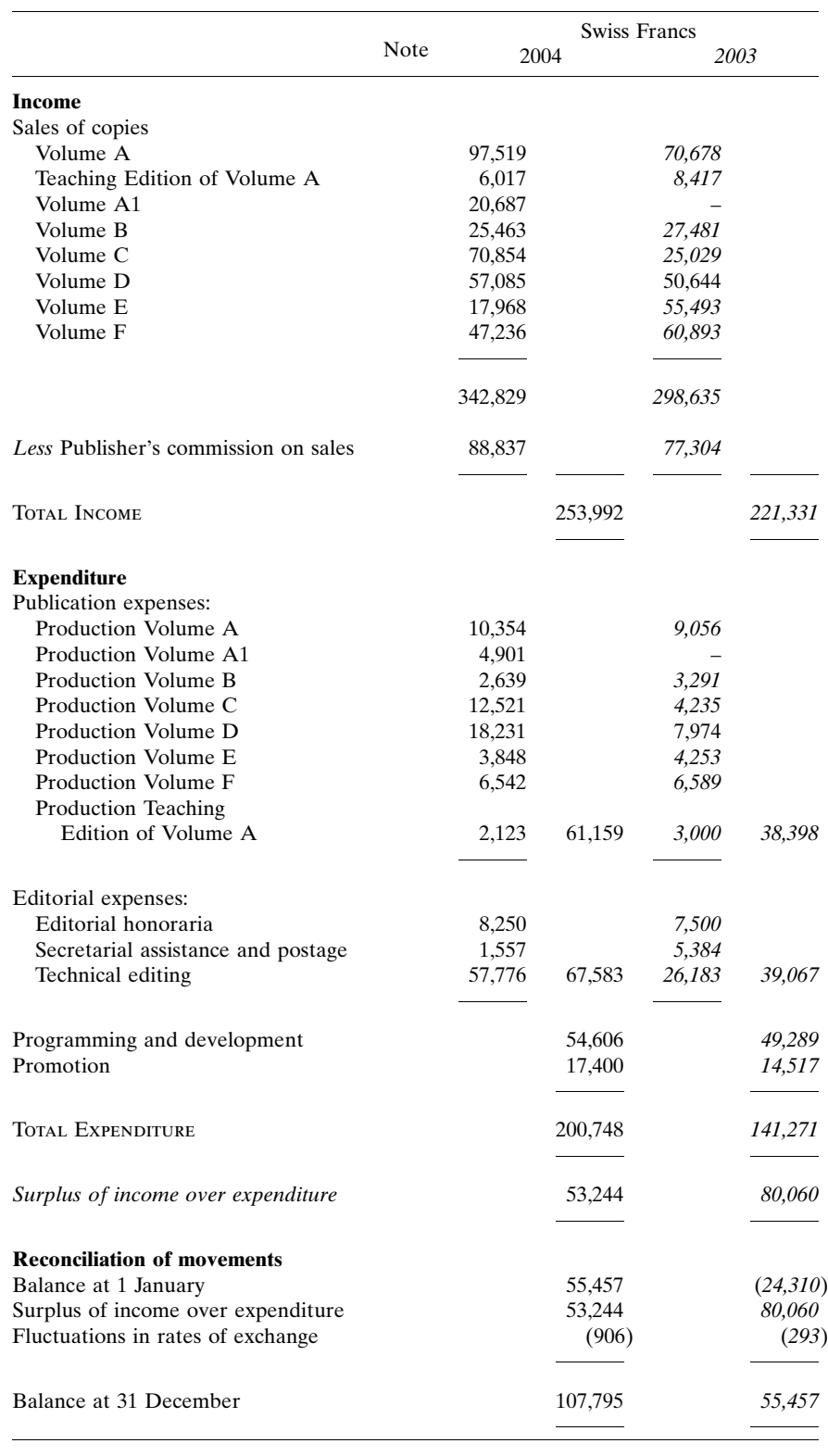




\section{international union of crystallography}

Table 24

Publications and Journals Development Fund Account for the year ended 31 December 2004.

\begin{tabular}{|c|c|c|c|c|c|}
\hline & & & Swiss $\mathrm{F}$ & Francs & \\
\hline & Note & 200 & & 200 & \\
\hline Income & & & & & \\
\hline Investment income & 15.7 & & 18,671 & & 16,055 \\
\hline Expenses & & & & & \\
\hline Computer expenses: & & & & & \\
\hline Programming and development & & 586,059 & & 444,039 & \\
\hline Recharged to other funds & & $(586,059)$ & - & $(444,039)$ & - \\
\hline Electronic Publishing Committee/ & & & & & \\
\hline Section Editors’ Meeting & & & 810 & & 2,576 \\
\hline Special Issue deficit & & & & & \\
\hline charged from other funds & & & 28,686 & & 44,773 \\
\hline NeXus & & & - & & 3,422 \\
\hline STAR/CIF & & & 57,243 & & 2,688 \\
\hline Promotion & & & 156,759 & & 130,785 \\
\hline Promotion recharged to other funds & & & $(156,759)$ & & $(130,785)$ \\
\hline Web input & & & 998 & & 2,931 \\
\hline Journal subscription subsidies & & & 46,301 & & 30,094 \\
\hline Depreciation of computer equipment & & & 22,605 & & 46,262 \\
\hline TOTAL EXPENDITURE & & & 156,643 & & 132,746 \\
\hline Deficit of income over expenditure & & & $(137,972)$ & & $(116,691)$ \\
\hline Reconciliation of movements & & & & & \\
\hline Balance at 1 January & & & 903,466 & & 774,936 \\
\hline Transfers from other funds & & & & & \\
\hline Acta Crystallographica & & & - & & 250,000 \\
\hline Deficit of income over expenditure & & & $(137,972)$ & & $(116,691)$ \\
\hline Fluctuations in rates of exchange & & & $(6,377)$ & & $(4,779)$ \\
\hline Balance at 31 December & & & 759,117 & & 903,466 \\
\hline
\end{tabular}

Table 25

Research and Education Fund Account for the year ended 2004

\begin{tabular}{|c|c|c|c|c|c|}
\hline & & & Swiss & Francs & \\
\hline & Note & & 2004 & & 003 \\
\hline Income & & & & & \\
\hline Investment income & 15.7 & & 22,225 & & 21,433 \\
\hline Donations & & & - & & 3,288 \\
\hline Total Income & & & 22,225 & & 24,721 \\
\hline Expenditure & & & & & \\
\hline Young Scientists' Support & & 119,382 & & 146,873 & \\
\hline Visiting Professorship Programme & & - & & 6,179 & \\
\hline Africa PhD Support & & 5,040 & & 5,963 & \\
\hline TOTAL EXPENDITURE & & & 124,422 & & 159,015 \\
\hline Deficit of income over expenditure & & & $(102,197)$ & & $(134,294)$ \\
\hline Reconciliation of movements & & & & & \\
\hline Balance at 1 January & & & $1,013,406$ & & $1,013,061$ \\
\hline Transfers from other funds & & & & & \\
\hline Acta Crystallographica & & & - & & 140,000 \\
\hline Deficit of income over expenditure & & & $(102,197)$ & & $(134,294)$ \\
\hline Fluctuations in rates of exchange & & & $(7,591)$ & & $(5,361)$ \\
\hline Balance at 31 December & & & 903,618 & & $1,013,406$ \\
\hline
\end{tabular}

Table 26

Ewald Fund Account for the year ended 31 December 2004

\begin{tabular}{|c|c|c|c|}
\hline & & & \\
\hline & Note & 2004 & 2003 \\
\hline Income & & & \\
\hline Investment income & 15.7 & 12,280 & 11,452 \\
\hline Grants & & - & 63 \\
\hline Total Income & & 12,280 & 11,515 \\
\hline Expenditure & & & \\
\hline Ewald Prize & & 743 & \\
\hline Surplus of income over expenditure & & 11,537 & 11,515 \\
\hline Reconciliation of movements & & & \\
\hline Balance at 1 January & & 491,942 & 458,029 \\
\hline Transfer from other Funds & & & \\
\hline Journal of Applied Crystallography & & - & 25,000 \\
\hline Surplus of income over expenditure & & 11,537 & 11,515 \\
\hline Fluctuations in rates of exchange & & $(4,194)$ & $(2,602$ \\
\hline Balance at 31 December & & 499,285 & 491,942 \\
\hline
\end{tabular}

Table 27

Newsletter Fund Account for the year ended 2004

Note $\quad 20044^{\text {Swiss Francs }} 2003$

Income

Income from advertisements

Expenditure

Editorial honoraria

Editorial expenses

Newsletter printing and distribution

Advertising costs

Total EXPENDiture

Deficit of income over expenditure

\section{Reconciliation of movements}

Balance at 1 January

Transfers from other funds Acta Crystallographica Journal of Applied Crystallography

Deficit of income over expenditure

Current year

Prior year

Fluctuations in rates of exchange

Balance at 31 December 230,075

229,721 